\title{
Research Article \\ Effects of Geofoam Panels on Static Behavior of Cantilever Retaining Wall
}

\author{
Navid Hasanpouri Notash $\mathbb{I D}^{1,2}$ and Rouzbeh Dabiri $\mathbb{i D}^{2}$ \\ ${ }^{1}$ Department of Civil Engineering, East Azerbaijan Science and Research Branch, Islamic Azad University, Tabriz, Iran \\ ${ }^{2}$ Department of Civil Engineering, Tabriz Branch, Islamic Azad University, Tabriz, Iran \\ Correspondence should be addressed to Rouzbeh Dabiri; rouzbeh_dabiri@iaut.ac.ir
}

Received 6 July 2017; Revised 18 October 2017; Accepted 26 November 2017; Published 30 January 2018

Academic Editor: Pier Paolo Rossi

Copyright ( $) 2018$ Navid Hasanpouri Notash and Rouzbeh Dabiri. This is an open access article distributed under the Creative Commons Attribution License, which permits unrestricted use, distribution, and reproduction in any medium, provided the original work is properly cited.

\begin{abstract}
Geofoam is one of the geosynthetic products that can be used in geotechnical applications. According to researches, expanded polystyrene (EPS) geofoam placed directly against a rigid retaining wall has been proposed as a strategy to reduce static loads on the wall. This study employed a finite difference analysis using a 2-D FLAC computer program by considering yielding and nonyielding states for retaining walls to explore the effectiveness of geofoam panels in improving the static performance of cantilever retaining walls. Retaining walls at heights of 3, 6, and 9 meters and geofoam panels with densities of 15, 20, and 25 $\left(\mathrm{kg} / \mathrm{m}^{3}\right)$ at three relative thicknesses of $t / H=0.05,0.2$, and 0.4 were modelled in this numerical study. In addition, the performance of the double EPS buffer system, which involves two vertical geofoam panels, in retaining walls' stability with four panel spacing $(50,100,150$, and $200 \mathrm{~cm})$ was also evaluated in this research. The results showed that use of EPS 15 with density equal to $15\left(\mathrm{~kg} / \mathrm{m}^{3}\right)$ which has the lowest density among other geofoam panels has a significant role in reduction of lateral stresses, although the performance of geofoam in nonyielding retaining walls is better than yielding retaining walls.
\end{abstract}

\section{Introduction}

Studies have shown that compressible materials between a rigid retaining wall and backfill reduced static [1-7] and dynamic [8-10] forces on the wall. Nowadays, panels with low density are used. Expanded polystyrene, which is one of the geosynthetic products known as geofoam, is a compressible material. Geofoam is one of the geosynthetic materials that are made of foam. Geofoam is very practical in geotechnical engineering due to its low bulk weight versus soil bulk weight and high compressibility, rapid and simple implementation, thermal insulation, and resistance against water absorption. It can be used in retaining walls, road construction projects as light fillers, and to reduce stress due to vertical loads in the base and subbase layers $[3,11,12]$. Generally, the main goals of the present study include an evaluation of the effect of geofoam's thickness and density, effect of using two vertical geofoam panels, effect of the sectional shape of geofoam (rectangular and trapezoidal) on displacements, and static forces on the cantilever retaining wall. It should be noted that in the present research, the mechanical behavior of the cantilever retaining wall has been assumed in two yielding and nonyielding states and the results were evaluated.

\section{Literature Review}

Compressible materials were placed behind rigid retaining walls by Partos and Kazaniwsky in 1987 to reduce static in situ forces (field study) [1]. In 1992, numerical analyses were conducted by Karpurapu and Bathurst [2] using finite element software. According to the study conducted by Karpurapu and Bathurst, it has been shown that compressible materials (later researchers have labelled them as geofoam and classified them within geosynthetic products) behind retaining walls reduced forces on the retaining wall. Generally, according to the results obtained in this research, an increase in soil lateral strain will reduce lateral forces [2]. Based on the conclusions of these researchers, an increase in 
the thickness of compressible material reduces soil lateral stresses. In addition, in a compressible matter with similar thickness, a reduction of the elasticity modulus of compressible matter causes a reduction of soil lateral stresses [2]. The effect of geofoam in the reduction of static forces on a nonyielding retaining wall has been shown by numerical and physical modelling [13]. Trandafir and Bartlett studied the performance of two geofoam panels with a density of $25 \mathrm{~kg} / \mathrm{m}^{3}$ in the reduction of seismic forces on a nonyielding rigid retaining wall (9 meters). Finite element software Quake/W (GEO-SLOPE International Ltd., 2004) has been used in this study. One of the panels is placed against the retaining wall and the other one is placed inside the embankment at a certain distance from the first panel. Analysis of the seismic performance of two geofoam panels shows that the performance of geofoam is a function of the distance between panels. Therefore, increasing the distance between two geofoam panels will increase their seismic performance and such an increase continues for a favorable distance. Afterwards, there is no increase in the seismic performance of geofoams in spite of an increase in the distance between two panels [8]. Numerical study conducted by Trandafir et al. [14] to determine the lateral pressures on rigid nonyielding retaining walls with geofoam inclusion for various wall heights and EPS panel thickness of $t=1.2 \mathrm{~m}$ by using finite element software Sigma/W (GEO-SLOPE International Ltd., 2008) showed that specific combinations of geofoam panel thickness and retaining wall height may induce plastic strains in the geofoam. An elastoplastic constitutive model was used to simulate the behavior of geofoam panel in this study. Finite difference analyses using FLAC 2D software by Ertugrul and Trandafir indicate that relative flexibility of the wall $(\mathrm{dw})$ and relative stiffness of the deformable geofoam layer (Ei/ti) have an important role in reducing the lateral earth pressure on cantilever retaining walls. According to this research, it is concluded that as the wall flexibility increases, load reduction potential of the geofoam buffers decreases [15]. Recent research conducted by AbdelSalam et al. by using the finite element modelling code (PLAXIS 3D) [16] showed that EPS inclusions have an effective role on local and global geotechnical stability of flexible walls. According to this study, at an EPS thickness ratio of $t / H=0.13$, factor of safety against overturning increases up to $40 \%$. However, sensitivity analyses of the EPS geofoam performance in relation to the thickness ratio of geofoam panel indicate that there is an optimum thickness ratio at which the factors of safety against overturning and sliding are maximized.

\section{Numerical Modelling and Material Properties}

The dimensions required for modelling cantilever retaining walls are shown in Table 1 . All the retaining walls have been modelled on a 9-metre thick dense sand layer. Studies conducted by FLAC show that the ratio of embankment length higher than 5 meters to the elevation of the retaining wall has a low effect on wall response $[9,17]$. Therefore, backfill length behind retaining walls is 45 meters for all models. Figure 1 shows the boundary
TABLE 1: Cantilever retaining wall dimensions [18].

\begin{tabular}{|c|c|c|c|c|c|}
\hline$H(\mathrm{~m})$ & $B(\mathrm{~m})$ & $t_{b}(\mathrm{~m})$ & $t_{s}(\mathrm{~m})$ & $b_{t}(\mathrm{~m})$ & $b_{h}(\mathrm{~m})$ \\
\hline & $\begin{array}{c}1 \\
\vdots \\
\vdots \\
\vdots\end{array}$ & $k b_{t \rightarrow}$ & $-b_{h} \rightarrow$ & & \\
\hline 3 & 2.1 & 0.3 & 0.3 & 0.6 & 1.2 \\
\hline 6 & 4.2 & 0.6 & 0.6 & 1.2 & 2.4 \\
\hline 9 & 6.3 & 0.9 & 0.9 & 1.8 & 3.6 \\
\hline
\end{tabular}

condition of yielding and nonyielding retaining walls. Figure 1(a) shows that the bottom part of the model in the horizontal and right directions, and the left and right sides of the model in the horizontal direction have a closed boundary condition in the yielding retaining wall. Figure 1(b) shows that in addition to the above, the exterior of the retaining wall (stem) in the horizontal direction has a closed boundary condition in nonyielding retaining walls. Meshing for modelling the 3-and 6-metre retaining walls has been chosen by the square elements of 0.3-metre dimensions and meshing of the 9-metre retaining wall has been chosen by the square elements of 0.45-metre dimensions.

Specifications of the cantilever retaining wall and soils used in the research are shown in Table 2. In the numerical model of the cantilever retaining wall, a linear elastic behavioral model has been used and the Mohr-Coulomb model has been used for modelling soils. Backfill behind the retaining wall and the soil used in the foundation of walls is dense sand [10].

Three types of EPS geofoams, such as EPS15, EPS20, and EPS 25 with 15,20 , and $25 \mathrm{~kg} / \mathrm{m}^{3}$ density, have been used in the present research. The Mohr-Coulomb model has been used for the numerical modelling of EPS geofoam panels. The mechanical properties of EPS20 and EPS25 were obtained from relations proposed by researchers based on Table 3, and the mechanical properties of EPS15 were obtained from the research conducted by Zarnani and Bathurst [9]. The EPS geofoam properties are presented in Table 4 that have been used in this numerical study.

The interface friction angle between the soil and wall was constrained to the internal friction angle via the relationship $\delta_{\text {soil-wall }}=(2 / 3) \phi_{\text {soil }}$. The interface friction angles between soil-geofoam and geofoam-wall were considered $26^{\circ}[10]$ and $30^{\circ}$ [19], respectively.

According to the FLAC manual, both normal $\left(k_{n}\right)$ and shear $\left(k_{s}\right)$ stiffness are set to ten times the equivalent stiffness of the stiffest neighboring zone [22], 


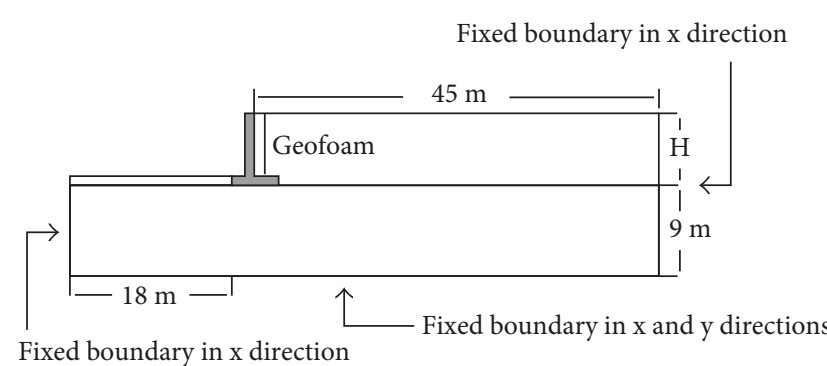

(a)

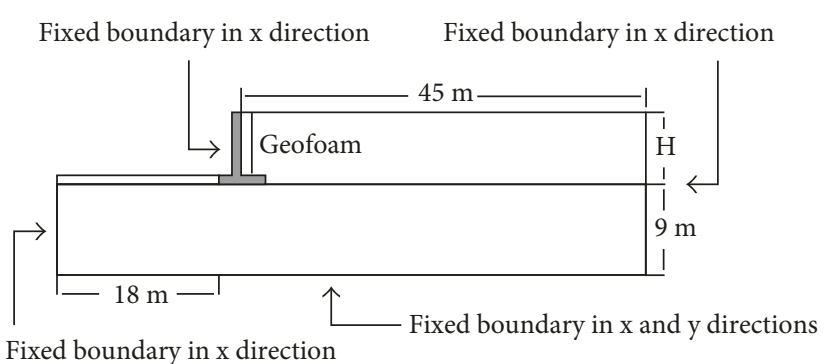

(b)

Figure 1: Cantilever retaining walls' boundary conditions. (a) Yielding retaining wall. (b) Nonyielding retaining wall.

TABLE 2: Material properties.

\begin{tabular}{lccc}
\hline & & Material & Foundation soil \\
Property & Backfill soil & 20 & 24 \\
\hline Unit weight $\left(\mathrm{kN} / \mathrm{m}^{3}\right)$ & 18 & 100 & $25 \times 10^{3}$ \\
Young's modulus $(\mathrm{MPa})$ & 60 & 0.33 & 0.15 \\
Poisson's ratio & 0.33 & 40 & - \\
Friction angle $\left({ }^{\circ}\right)$ & 35 & 0 & - \\
Cohesion $(\mathrm{kPa})$ & 0 & & - \\
\hline
\end{tabular}

TABLE 3: Recommended correlations for the EPS geofoam design based on literature.

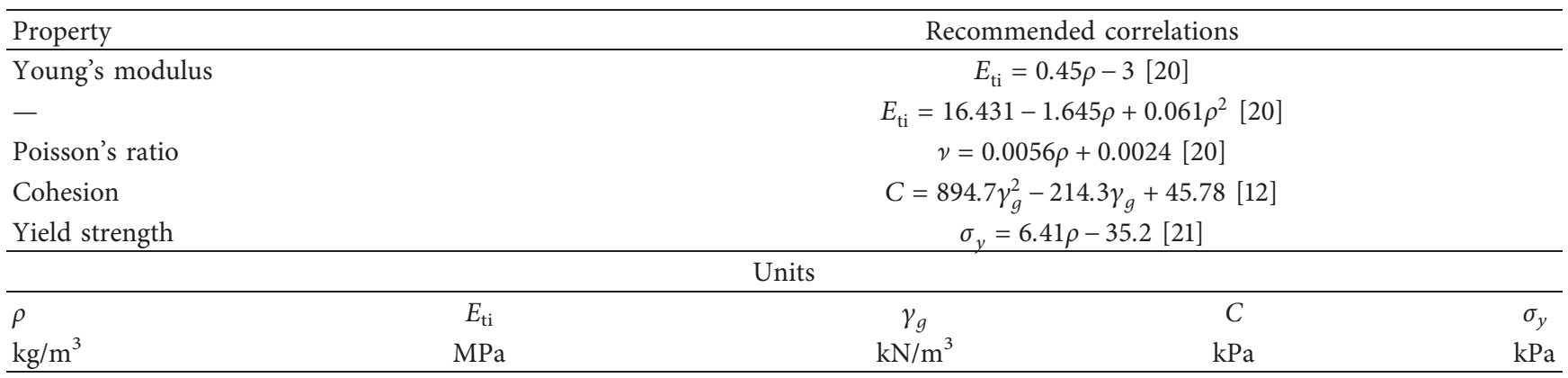

TABLE 4: EPS properties.

\begin{tabular}{lccc}
\hline Type & EPS15 & EPS20 & EPS25 \\
\hline Density $\left(\mathrm{kg} / \mathrm{m}^{3}\right)$ & 15 & 20 & 25 \\
Young's modulus $(\mathrm{MPa})$ & 4.31 & 6.97 & 10.84 \\
Poisson's ratio & 0.1 & 0.11 & 0.14 \\
Cohesion $(\mathrm{kPa})$ & 27 & 38.71 & 48.12 \\
Yield strength $(\mathrm{kPa})$ & 54 & 93 & 125 \\
\hline
\end{tabular}

$$
k_{n}=k_{s}=10 \times \max \left[\frac{(K+4 / 3 G)}{\Delta z_{\min }}\right] .
$$

In this relation, $K$ is the bulk modulus, $G$ is the shear modulus, and $\Delta z_{\min }$ is the smallest dimension of the smallest span near the boundary under study [22]. In the equation mentioned above, the values of normal stiffness and shear stiffness have been considered equally. Concerning research conducted on retaining walls, shear stiffness has values lower than those of normal stiffness [23-25]. According to relation
2 , the shear stiffness of materials' interface is considered as 0.2 (equal to normal stiffness) [24],

$$
k_{s}=0.2 \times k_{n} \text {. }
$$

Equation (1) presents a reasonable time for calculation of equilibrium stiffness and materials on both sides of the interface. If materials on one side of the interface are more rigid than the other side, (1) should be considered in terms of the soft part. Therefore, the stiffness of the interface is 10 times the stiffness of the soft part, and this amount will be 


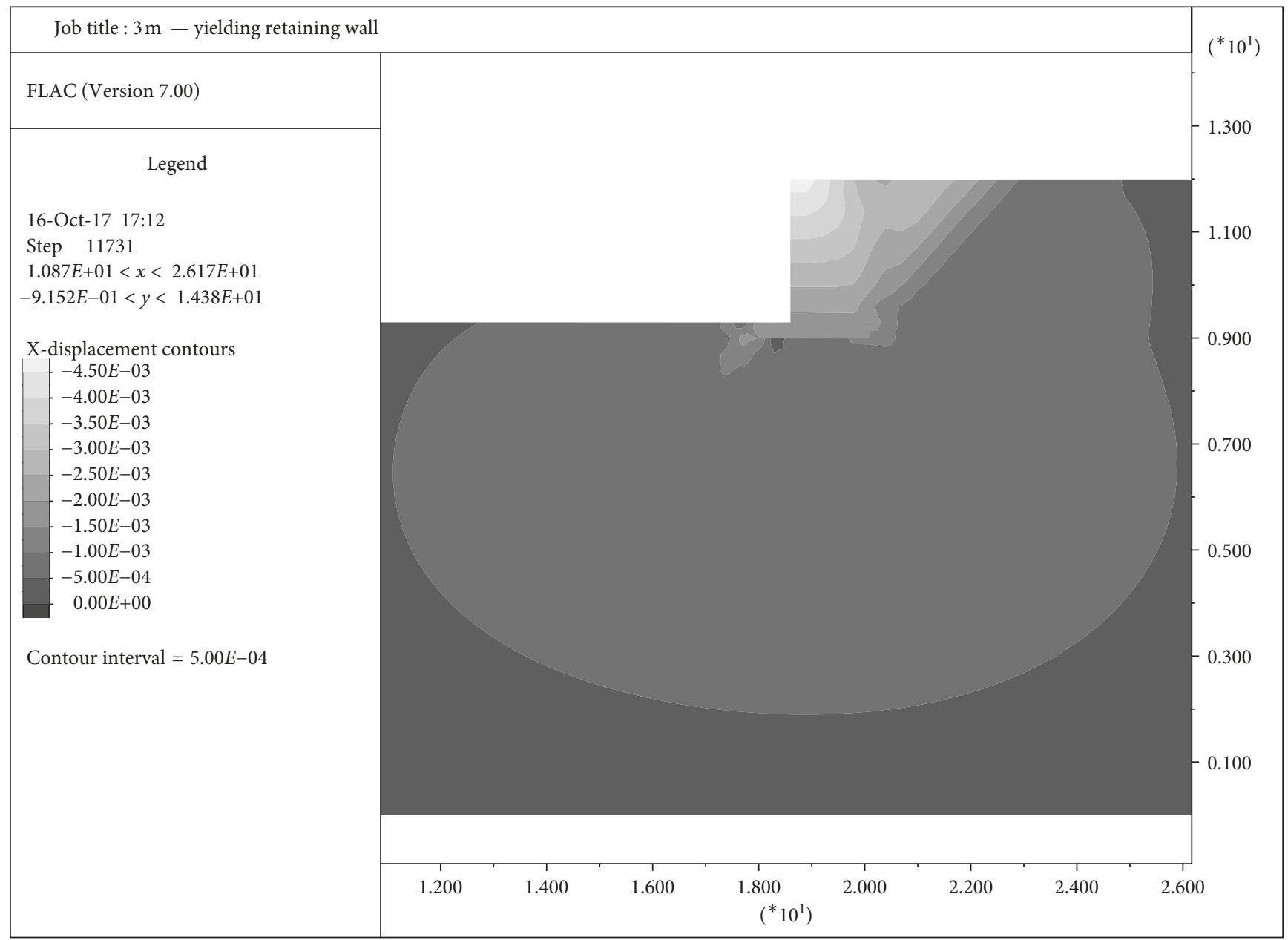

(a)

FIgURE 2: Continued. 


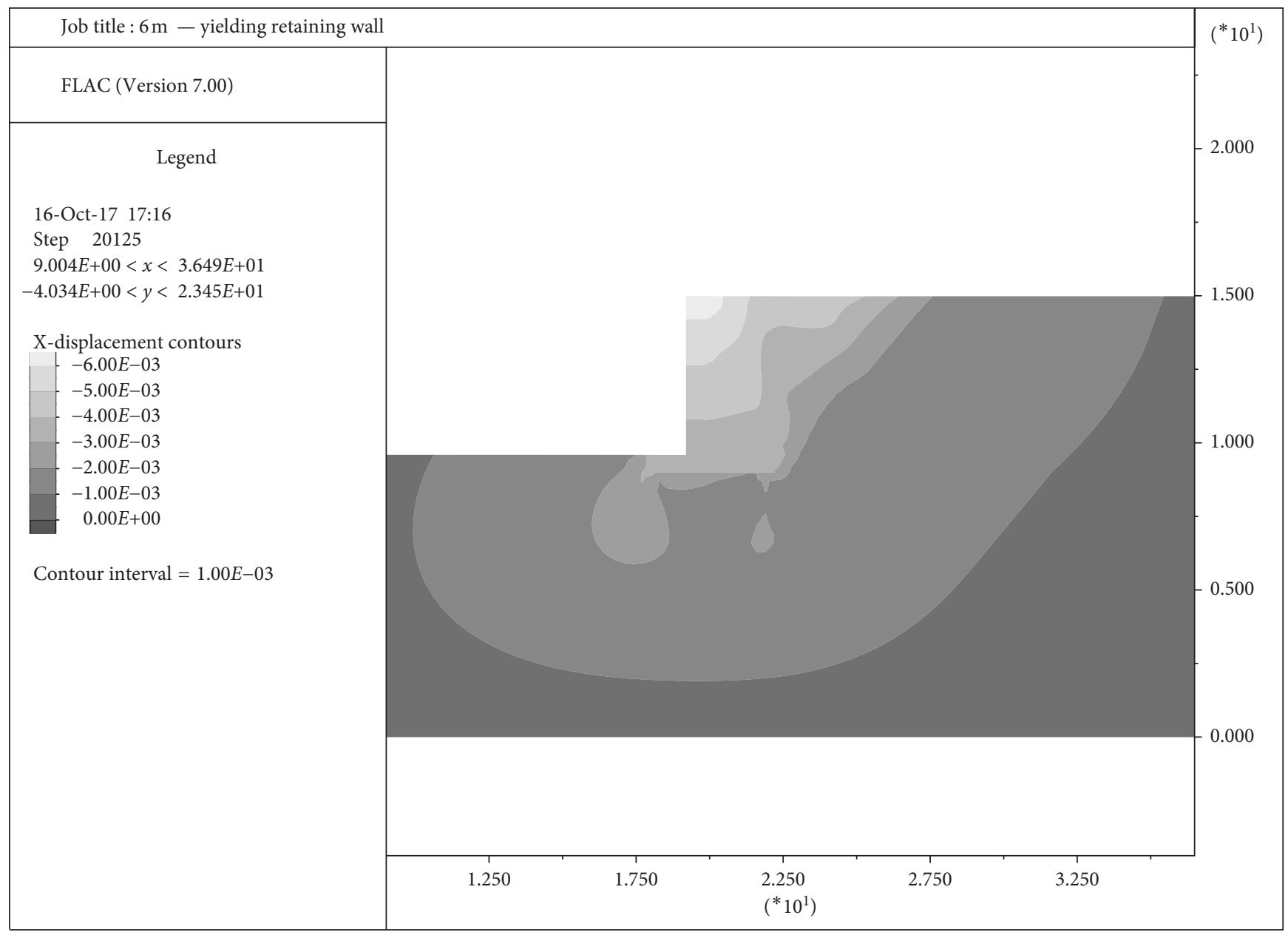

(b)

FIgUre 2: Continued. 


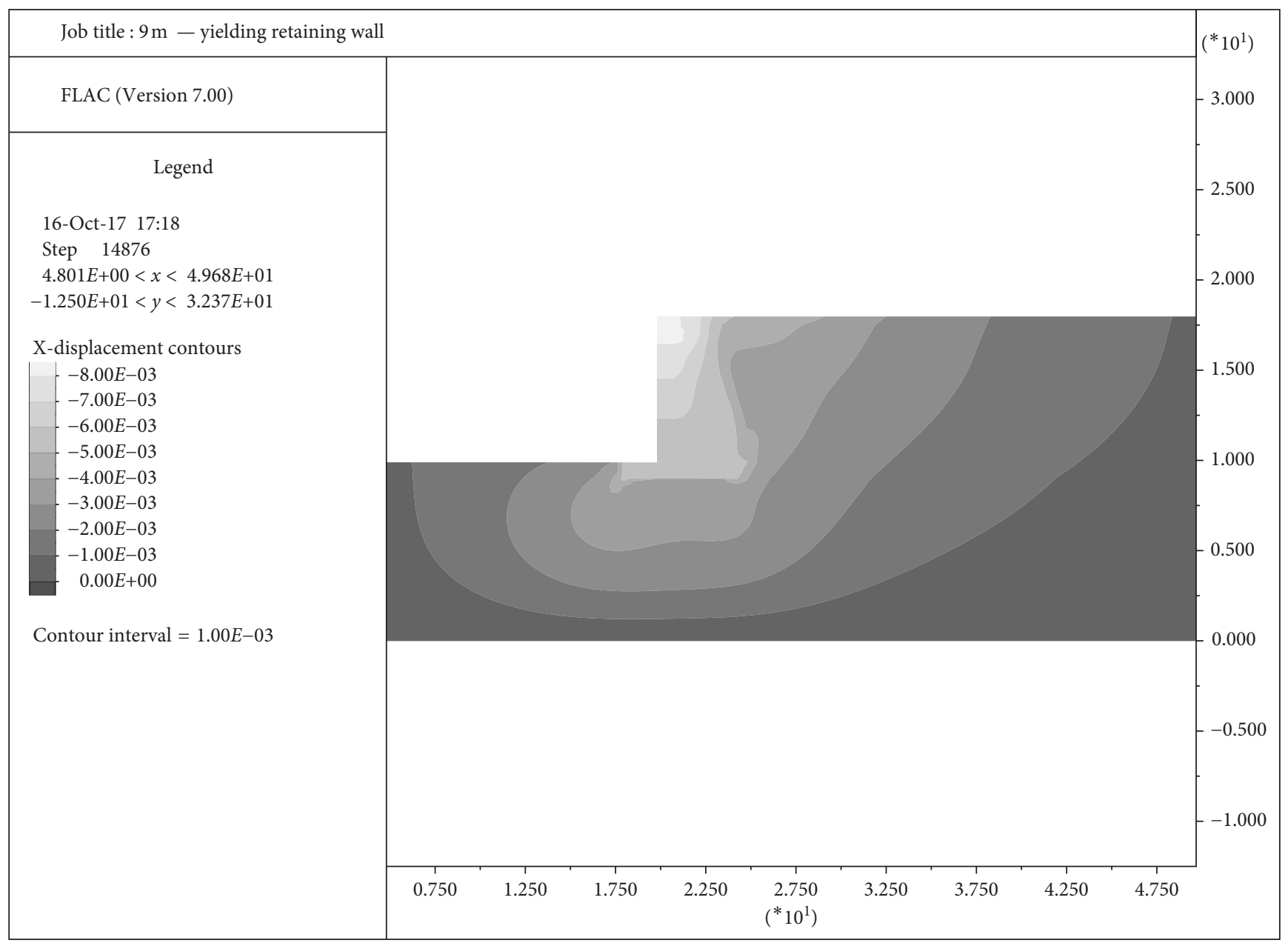

(c)

Figure 2: Horizontal displacement contours for yielding retaining walls: (a) $H=3 \mathrm{~m}$, (b) $H=6 \mathrm{~m}$, and (c) $H=9 \mathrm{~m}$.

acceptable [22]. However, values of normal interface stiffness between wall-foundation soil, wall-backfill soil, wallEPS, EPS-foundation soil, and EPS-backfill soil, according to Appendix A, varied between 146 and $4940 \mathrm{MPa}$ for $3 \mathrm{~m}$ and $6 \mathrm{~m}$ high wall and for $9 \mathrm{~m}$ high wall they varied between 97 and $3290 \mathrm{MPa}$. Figure 2 shows horizontal displacement contours $(\mathrm{m})$ for yielding retaining walls without using the geofoam panel.

\section{Results of Analysis}

4.1. Effects of Geofoam Thickness. As mentioned, the effect of geofoam on soil lateral displacement and statical forces on cantilever retaining walls with yielding and nonyielding boundary conditions has been studied in the present research. Figures 3(a)-3(c) indicate the distribution of forces across the height of retaining walls in yielding and nonyielding conditions without using geofoam. By assuming yielding conditions for the retaining wall, the lateral forces are between the rest and active states, assuming nonyielding boundary conditions. The biggest lateral force affects the retaining wall. Figures 3(d)-3(f) illustrate the lateral earth pressure distribution on yielding retaining walls in relatively different thicknesses of geofoam of EPS15. As can be observed, by increasing thickness of geofoam panel, lateral earth pressures reduced to those corresponding active state values. These results have good agreement with that reported by Ertugrul and Trandafir [15] for physical and numerical modelling of rigid (with a relative flexibility of $\mathrm{dw}=0$ ) and flexible (with a relative flexibility of $\mathrm{dw}=524$ ) cantilever retaining walls.

Figure 4 shows a reduction of forces on yielding and nonyielding retaining walls in case of using EPS15, EPS20, and EPS 25 with 15,20 , and $25 \mathrm{~kg} / \mathrm{m}^{3}$ density, respectively. A dimensionless parameter, $A_{P}$, is the isolation efficiency of geofoam panel to measure the reduction of wall force with and without using geofoam at different thicknesses of geofoam panel was calculated according to the following equation:

$$
A_{P}=\frac{P_{0}-P}{P_{0}},
$$

where $P_{0}$ and $P$ are the forces acting on the retaining wall with and without using the geofoam panel, respectively. 


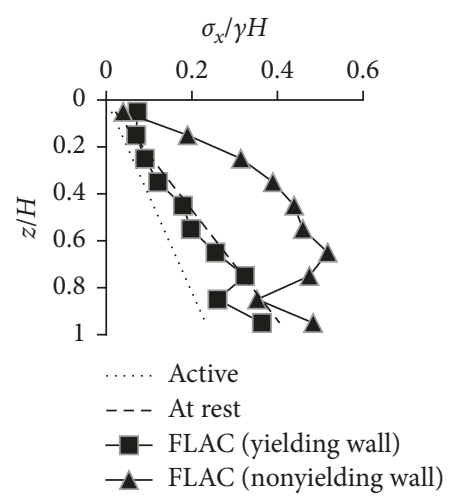

(a)

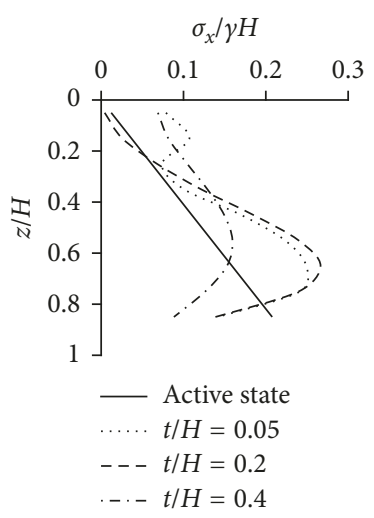

(d)

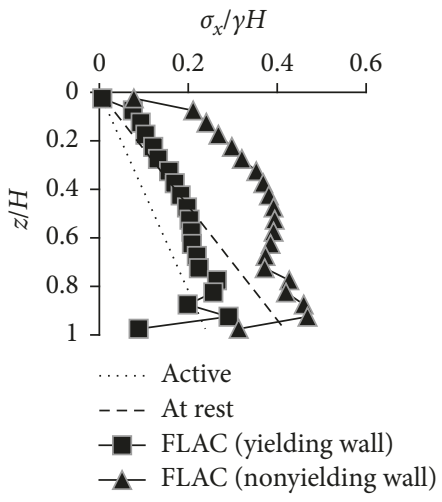

(b)

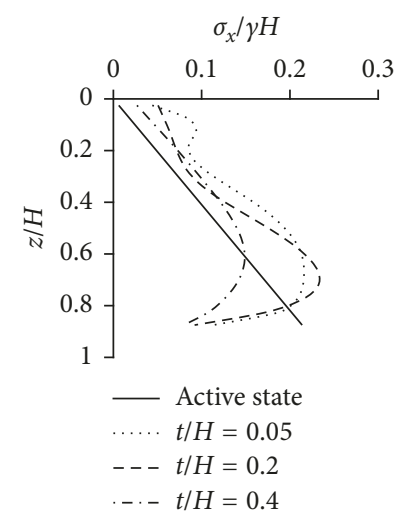

(e)

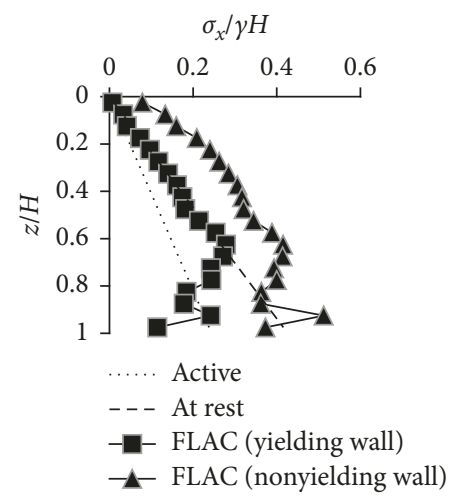

(c)

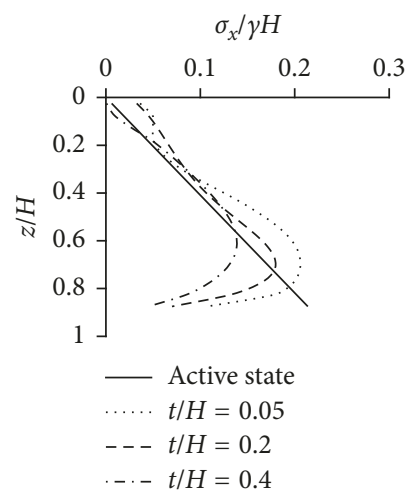

(f)

FIGURE 3: Lateral earth pressure distribution on the cantilever retaining walls: ( $a, b$, and $c$ ) yielding and nonyielding conditions without using geofoam and (d, e, and f) yielding condition by using EPS15. (a) $H=3 \mathrm{~m}$. (b) $H=6 \mathrm{~m}$. (c) $H=9 \mathrm{~m}$. (d) $H=3 \mathrm{~m}$. (e) $H=6 \mathrm{~m}$. (f) $H=9 \mathrm{~m}$.

It can be seen that the increasing thickness of geofoam reduces forces on retaining walls and geofoam efficiency is increased by a reduction of forces on the walls. These have been shown by Ertugrul and Trandafir for nonyielding retaining wall with using three different EPS geofoam panel thicknesses $(t / H=0.07,0.14$, and 0.28) [13]. As seen in the figure, the effect of geofoam in the reduction of forces on nonyielding retaining walls is higher than that for yielding walls. The effect of the EPS geofoam thickness ratio on reduction of lateral pressure in cases of using EPS15, EPS20, and EPS25 for yielding and nonyielding retaining walls is represented in Appendix B.

4.2. Effects of Geofoam Density. Figure 5 indicates the effect of geofoam density on static forces on the cantilever retaining walls at different thicknesses of geofoam. As seen in this figure, there is a general trend towards decreasing lateral pressures on nonyielding retaining walls with decreasing EPS density at equal thickness of geofoam panels. The results showed that use of EPS15 which has the lowest density among other geofoam panels has a significant role in reduction of lateral stresses on yielding and nonyielding retaining walls. However, the effect of EPS15 geofoam density on yielding retaining walls at a height of 6 meters is different from nonyielding retaining walls, which requires further studies. Figure 6 shows the effect of geofoam density with a relative thickness of $0.05 \mathrm{H}$ on the lateral displacement of soil in yielding and nonyielding walls, respectively. Lateral displacements of soil increase by a reduction in geofoam density. The increasing elevation of the wall increases lateral displacements of soil.

4.3. Effects of Number Geofoam Panels and Cross-Sectional Shape of Geofoam. The results showed that two geofoam panels had a more optimal effect on the reduction of seismic forces in nonyielding retaining walls [8]. In the present research, the effect of two geofoam panels on cantilever retaining walls was studied via static analysis. In order to compare the performance of two geofoam panels and one geofoam panel in the reduction of forces on the wall, two geofoam panels with $15 \mathrm{~kg} / \mathrm{m}^{3}$ density (EPS15) and a relative thickness of $0.4 \mathrm{H}$ (thickness of each panel is $0.2 \mathrm{H}$ ) at distances of 50,100, 150, and $200 \mathrm{~cm}$ were modelled and compared with the performance of one geofoam panel with a relative thickness of $0.4 \mathrm{H}$. Figures 7 (a) and 7 (b) show the effect of geofoam on the reduction of forces on yielding and nonyielding retaining walls at different distances of geofoam $(d)$. It should be noted that the distance $(d=0)$ relates with 


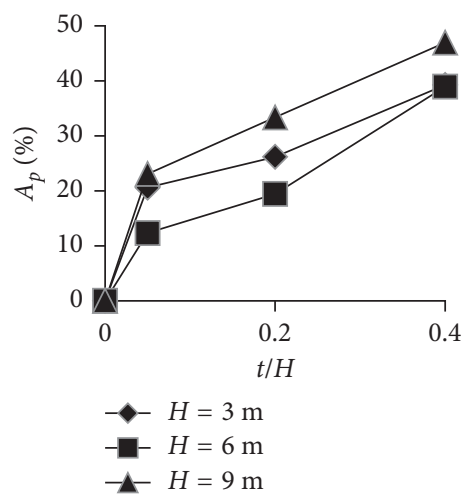

(a)

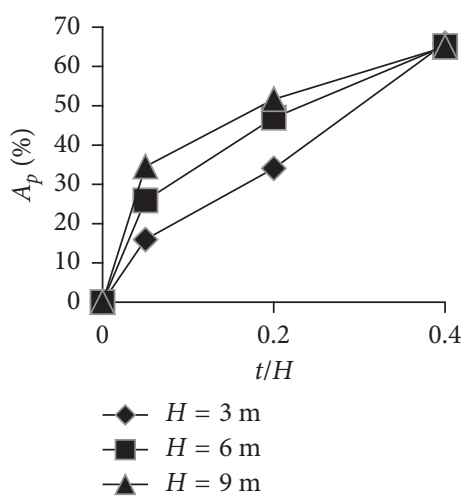

(d)

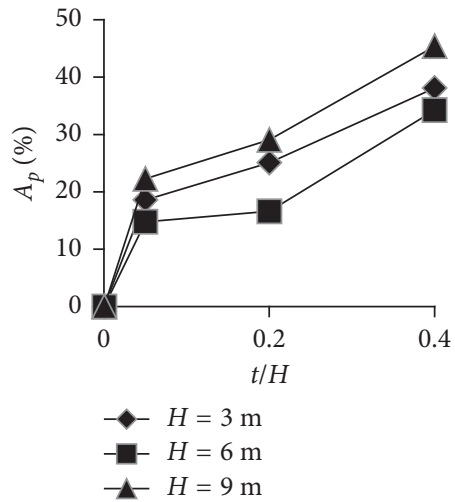

(b)

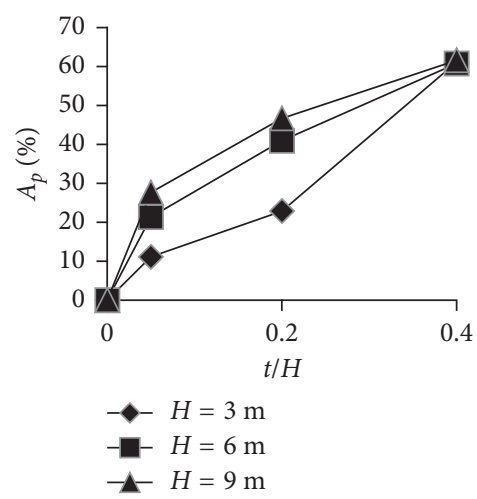

(e)

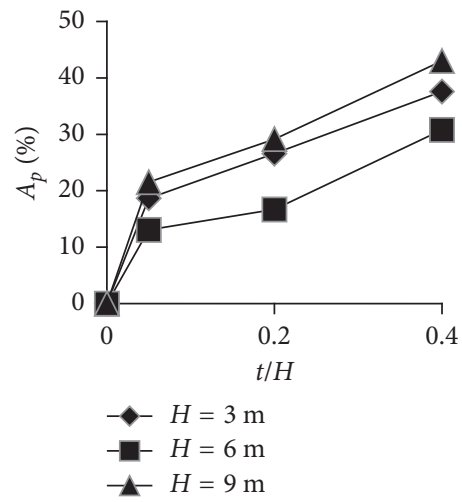

(c)

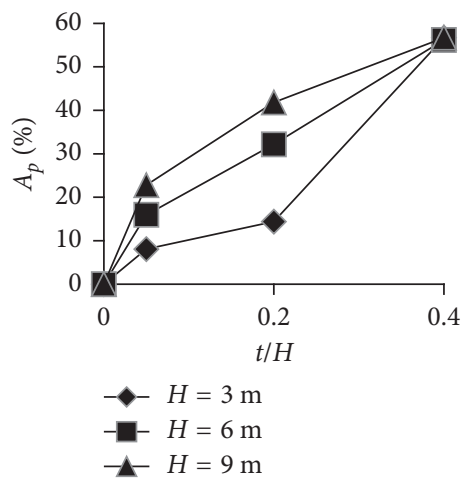

(f)

FIGURE 4: Influence of the geofoam thickness ratio on ( $a, b$, and $c)$ reduction of forces on the yielding retaining walls and (d, e, and $f$ ) reduction of forces on the nonyielding retaining walls. (a) EPS15. (b) EPS20. (c) EPS25. (d) EPS15. (e) EPS20. (f) EPS25.

one geofoam panel with a relative thickness of $0.4 \mathrm{H}$. According to the results, unlike a nonyielding retaining wall, using two geofoam panels is proper only in the 3-metre yielding retaining wall with a distance of $50 \mathrm{~cm}$. Finite element results of 9-meter rigid retaining wall by Trandafir and Bartlett [8] showed that by the use of double EPS buffer system, seismic load reduction efficiency of geofoam inclusions increases by almost 5\% at optimum EPS panel spacing of $d=90 \mathrm{~cm}$. According to their results, additional increase in the EPS panel spacing produces a decline in the seismic panels' performance. As seen in Figure 7(a), using two geofoam panels in the 3-metre yielding retaining wall improves geofoam efficiency about 5\% compared to a single rectangular geofoam panel of the same EPS volume. As shown in Figure $7(\mathrm{a})$, for $3 \mathrm{~m}$ high retaining wall, static performance of two geofoam panels with panels' spacing of $d=200 \mathrm{~cm}$ is obtained better than $d=100 \mathrm{~cm}$ and $d=150 \mathrm{~cm}$ in reduction of lateral forces. The reason for this is that at panels' spacing of $d=200 \mathrm{~cm}$, reduction in lateral pressures occurs due to the yielding of the soil at the distance between the two geofoam panels. As can be seen in Figure 7(b), the behavior of two geofoam panels in 6- and 9-meter nonyielding retaining walls are almost the same. According to the results obtained by Trandafir et al. regarding to the performance of one geofoam panel in reduction of lateral pressures on nonyielding retaining walls, EPS isolation efficiency (i) for a height range of 6 to 10 meters is approximately the same for a relative thickness of $t / H=0.4$ [14]. In the present study, the same result has been obtained by using two geofoam panels for 6- and 9-meter nonyielding retaining walls. Research indicated that a cross section of geofoam plays a considerable role in the reduction of forces on the retaining wall $[8,26]$. Also, research studies have indicated that the trapezoidal shape of geofoam behind the nonyielding retaining wall will have a more favorable effect on the reduction of seismic forces on the retaining wall [8]. In order to study the difference between performance of trapezoidal geofoam and the performance of rectangular geofoam in a static analysis state, modelling was done with geofoam EPS15. In this comparison, cross sections of trapezoidal geofoam and rectangular geofoam are considered equally. According to Figures 8(a) and 8(b), the trapezoidal geofoam has a better performance in the reduction of forces on retaining walls compared to one or two rectangular geofoam panels with a relative thickness of $0.4 \mathrm{H}$ and a distance of $50 \mathrm{~cm}$.

Figures 9 and 10 indicate the effect of one rectangular geofoam panel with a relative thickness of $0.4 \mathrm{H}$ and trapezoidal geofoam on lateral displacements of soil and also the distribution of forces on yielding and nonyielding retaining walls, respectively. As seen in the figures, trapezoidal geofoam 


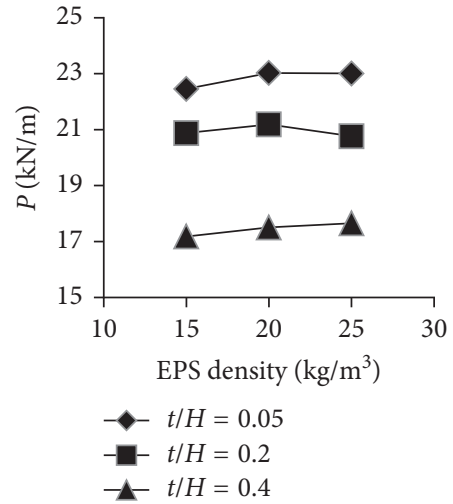

(a)

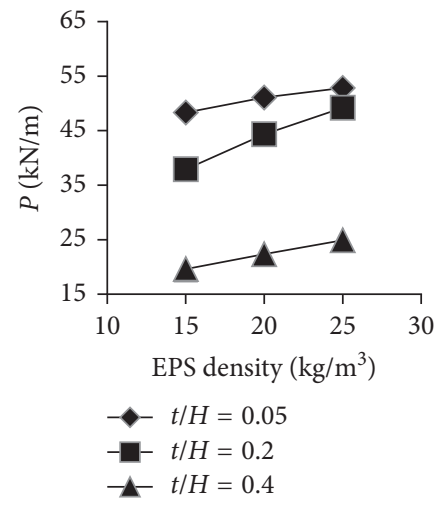

(d)

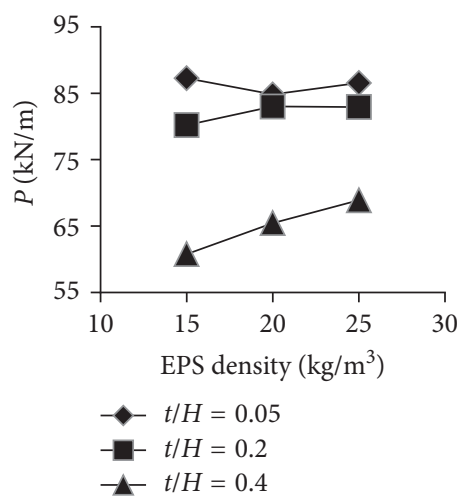

(b)

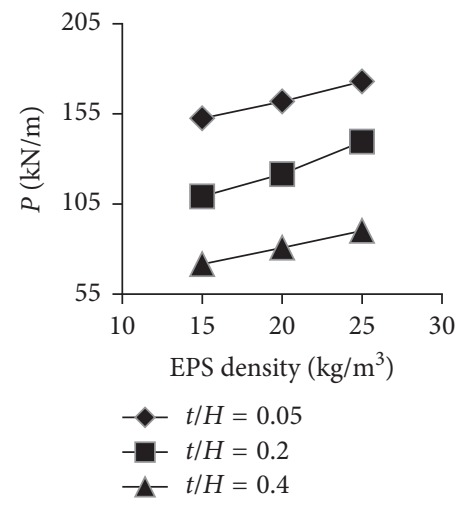

(e)

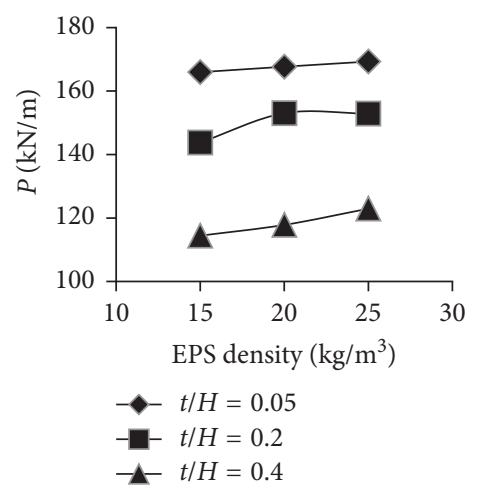

(c)

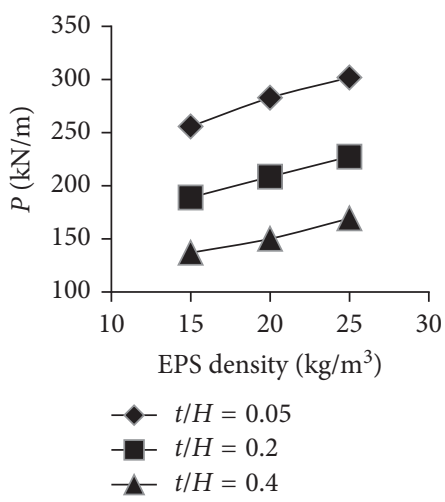

(f)

FiguRe 5: Influence of geofoam density on static forces on the cantilever retaining walls: (a, b, and c) yielding retaining walls and (d, e, and $\mathrm{f}$ ) nonyielding retaining walls. (a) $H=3 \mathrm{~m}$. (b) $H=6 \mathrm{~m}$. (c) $H=9 \mathrm{~m}$. (d) $H=3 \mathrm{~m}$. (e) $H=6 \mathrm{~m}$. (f) $H=9 \mathrm{~m}$.

increases soil lateral displacements and reduces forces on retaining walls compared to rectangular geofoam.

4.4. Effects of Stiffness of Geofoam. According to Zarnani and Bathurst with increasing EPS geofoam stiffness $(k=E / t)$, seismic isolation efficiency of EPS inclusion nonlinearly reduced [17]. Figure 11 shows the effect of stiffness of geofoam $(k=E / t)$ (ratio of elasticity modulus of geofoam to thickness of geofoam) on the reduction of forces on yielding and nonyielding retaining walls. As seen in the figure, when the stiffness of geofoam is decreased, geofoam performance increases via a reduction of forces.

4.5. Effects of Relative Stiffness of Geofoam. Figure 12 shows the effect of relative stiffness of geofoam $\left(E_{b} / E_{g}\right)$ (ratio of elasticity modulus of backfill behind retaining wall to elasticity modulus of geofoam panels under study) on the reduction of forces on yielding and nonyielding retaining walls. As can be seen in this figure, when the relative stiffness of geofoam is increased, forces on the retaining walls are reduced and geofoam performance increases via a reduction of forces. This has been shown by Ertugrul et al. for nonyielding retaining wall [13]. As seen in the figure, in nonyielding retaining wall and geofoam with the relative thickness of $0.4 \mathrm{H}$, wall height has no considerable effect on the static efficiency of geofoam panels. This result has been shown by Trandafir et al. [14].

4.6. Effect of Geofoam on Overturning Safety Factor of Retaining Wall. As mentioned, the effect of geofoam on soil lateral displacement and statical forces on the cantilever retaining walls with yielding and nonyielding boundary conditions has been studied in the present research. Table 5 indicates the safety factor of stability for the 3-, 6-, and 9metre yielding retaining walls without using geofoam. Figure 13 indicates the effect of geofoam, in the cases of using EPS15, EPS20, and EPS25, on the overturning safety factor of yielding retaining walls. According to the figure, the relative thickness of $t / H=0$ related to without using EPS geofoam panel. As seen in the figure, geofoam with the relative thickness of $0.05 \mathrm{H}$ is a reasonable selection for increasing the overturning safety factor of the cantilever retaining wall. However, relative thicknesses more than $0.2 \mathrm{H}$ are not recommended due to a reduction of resisting forces and stability of cantilever retaining walls. At a thickness of $0.4 \mathrm{H}$, the overturning safety factor of yielding retaining walls is reduced by $50 \%$.

\section{Conclusions}

In the present numerical study, finite difference software FLAC in 2D analysis state has been used. The main goal of the research is to study the effect of geofoam on the 


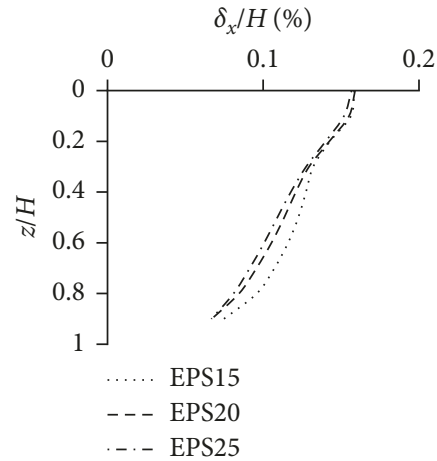

(a)

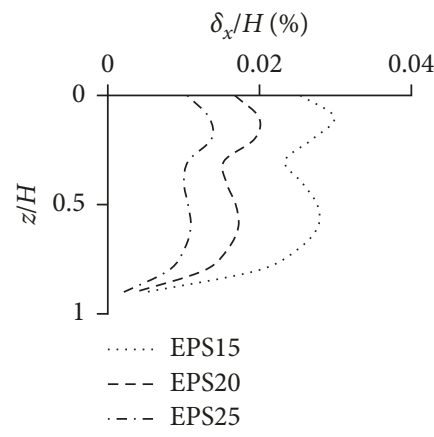

(d)

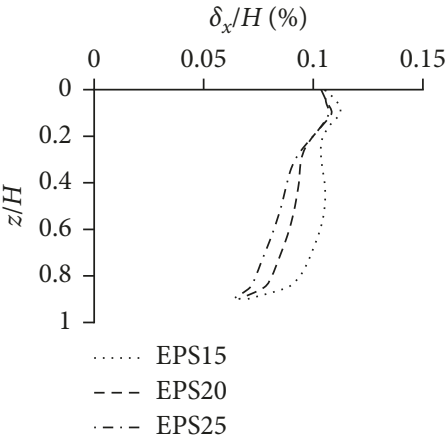

(b)

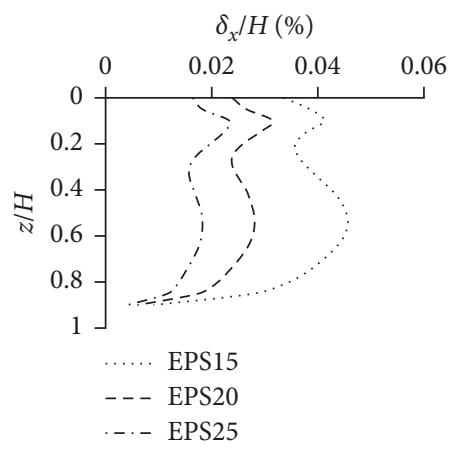

(e)

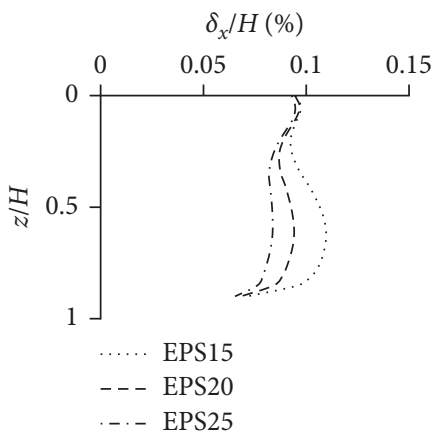

(c)

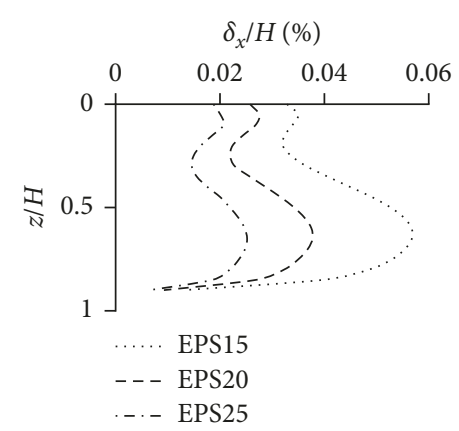

(f)

Figure 6: Influence of geofoam density with the relative thickness of $0.05 \mathrm{H}$ on the lateral displacements of soil: (a, b, and c) yielding retaining walls and (d, e, and f) nonyielding retaining walls. (a) $H=3 \mathrm{~m}$. (b) $H=6 \mathrm{~m}$. (c) $H=9 \mathrm{~m}$. (d) $H=3 \mathrm{~m}$. (e) $H=6 \mathrm{~m}$. (f) $H=9 \mathrm{~m}$.

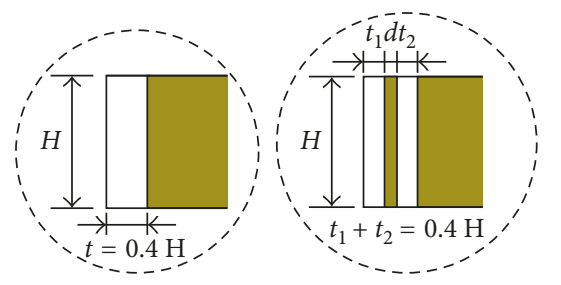

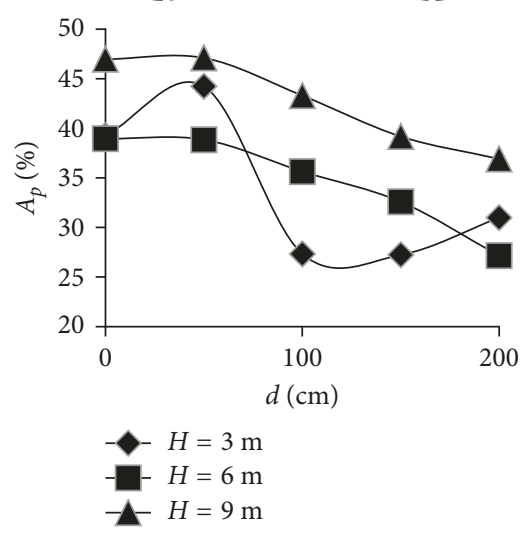

(a)

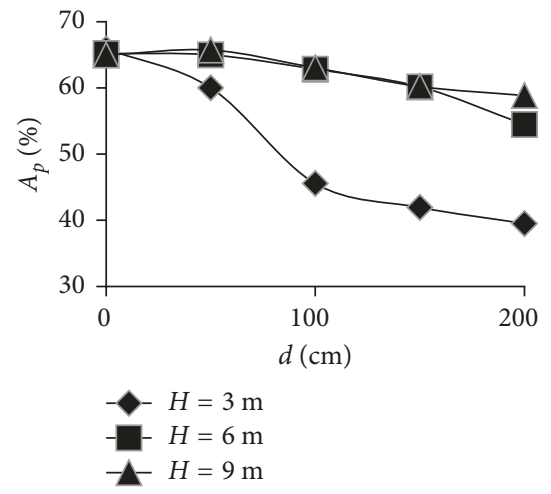

(b)

FIGURE 7: Effects of one geofoam panel and two geofoam panels with the relative thickness of $0.4 \mathrm{H}$ in various panel spacing on reduction of wall forces: (a) yielding retaining wall and (b) nonyielding retaining wall. 


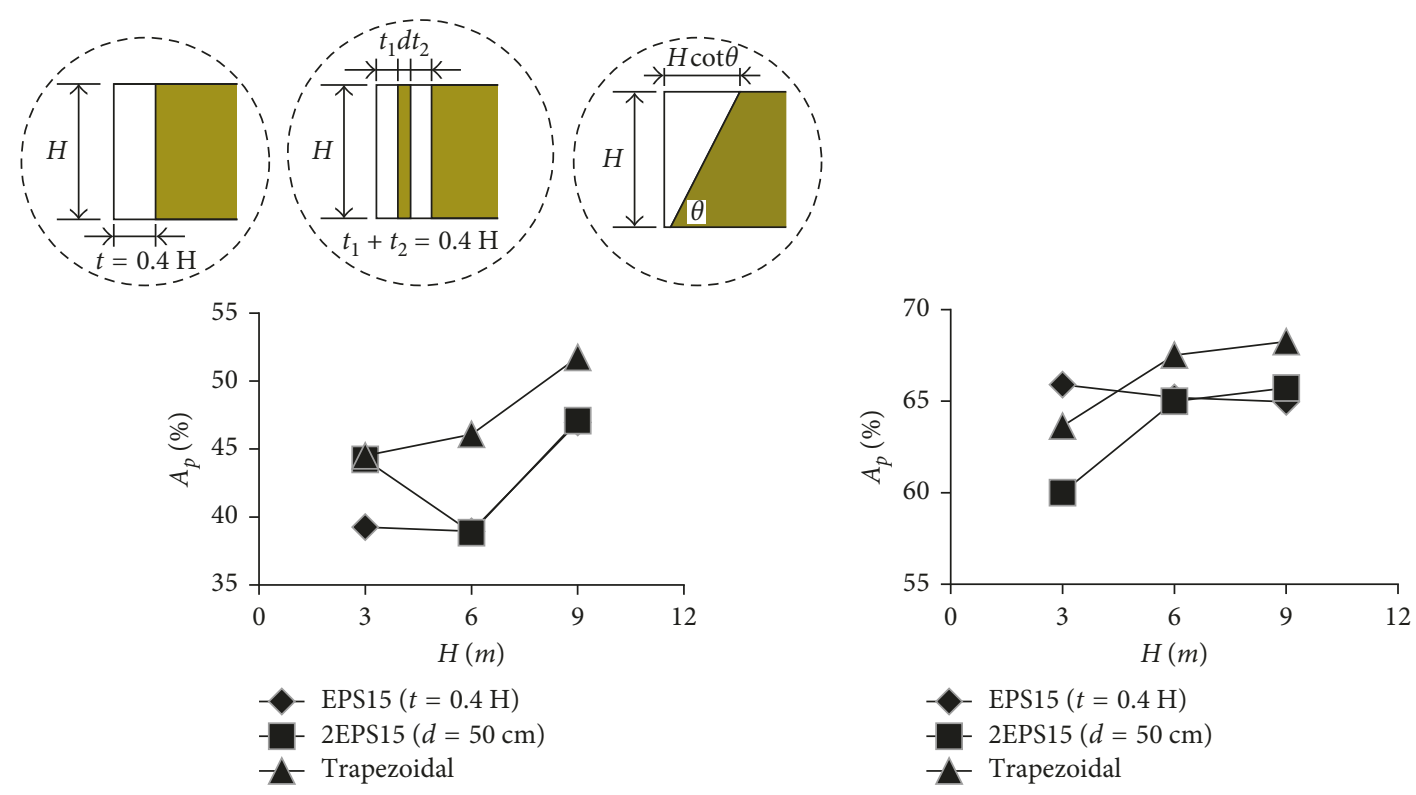

(a)

(b)

FiguRE 8: Effects of trapezoidal and rectangular geofoam panels on the reduction of wall forces: (a) yielding retaining wall and (b) nonyielding retaining wall.

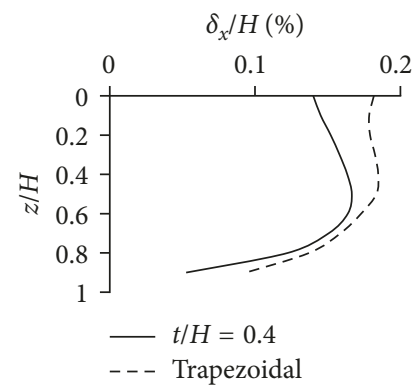

(a)

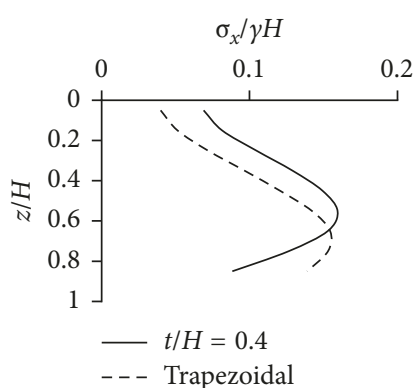

(d)

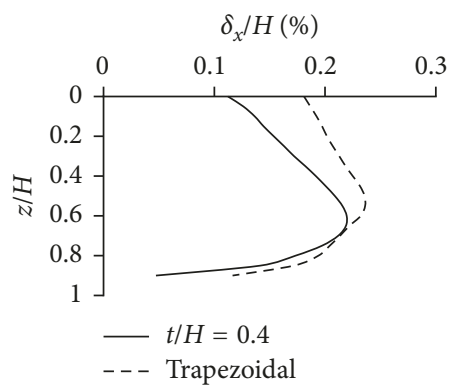

(b)

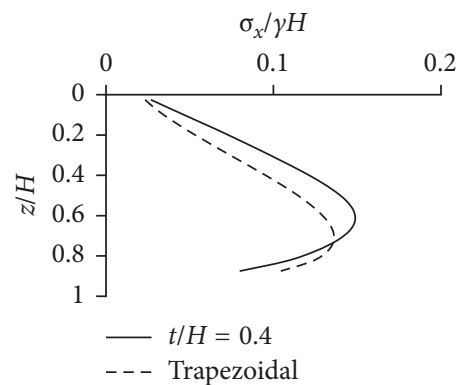

(e)

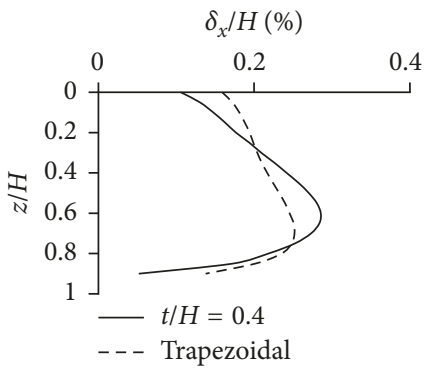

(c)

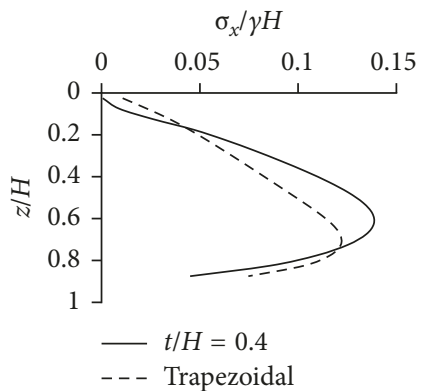

(f)

FIGURE 9: Effect of trapezoidal geofoam panel and one rectangular geofoam panel with the relative thickness of $0.4 \mathrm{H}$ on $(\mathrm{a}, \mathrm{b}$, and c) lateral displacements of soil and (d, e, and f) distribution of forces on yielding retaining walls. (a) $H=3 \mathrm{~m}$. (b) $H=6 \mathrm{~m}$. (c) $H=9 \mathrm{~m}$. (d) $H=3 \mathrm{~m}$. (e) $H=6 \mathrm{~m}$. (f) $H=9 \mathrm{~m}$.

behavioral improvement of cantilever retaining walls in static conditions. The results of the present research are as follows:

(1) According to results, increasing the geofoam thickness increases soil lateral displacement and reduces forces on cantilever retaining walls.
(2) Forces on cantilever retaining walls are reduced and soil lateral displacement is increased by a reduction of geofoam density with equal thickness.

(3) Two geofoam panels have no considerable effect on the reduction of static forces on yielding and nonyielding retaining walls. 


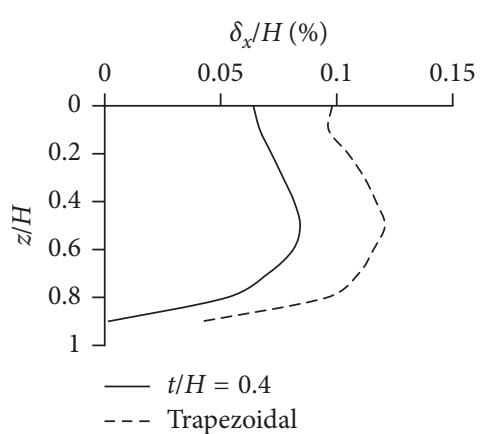

(a)

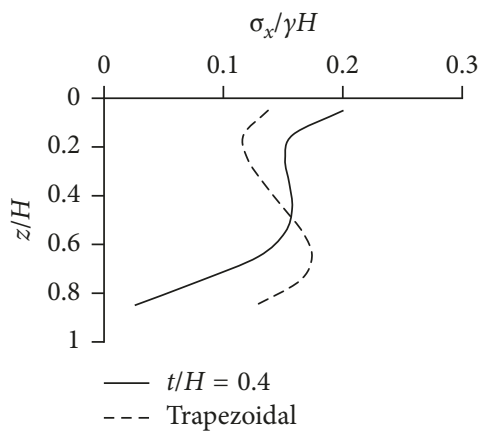

(d)

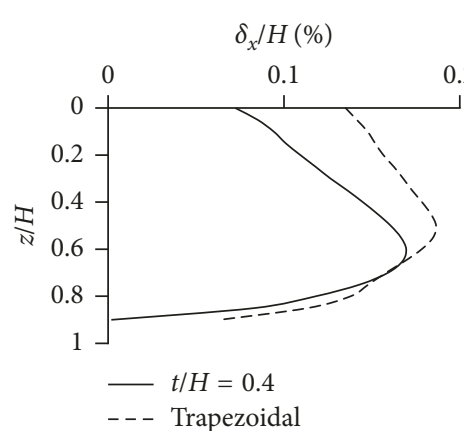

(b)

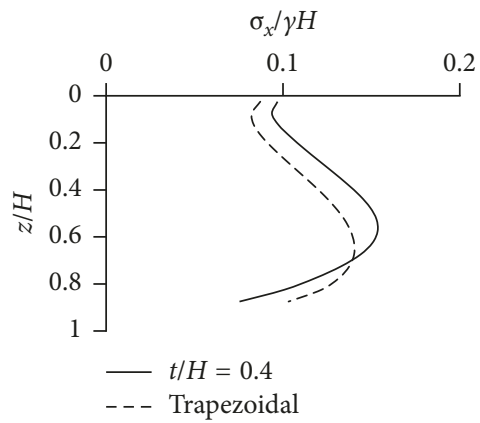

(e)

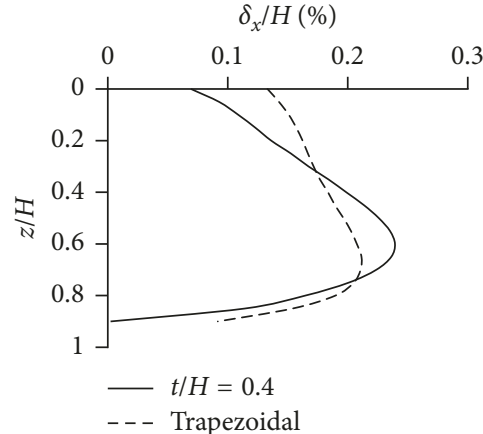

(c)

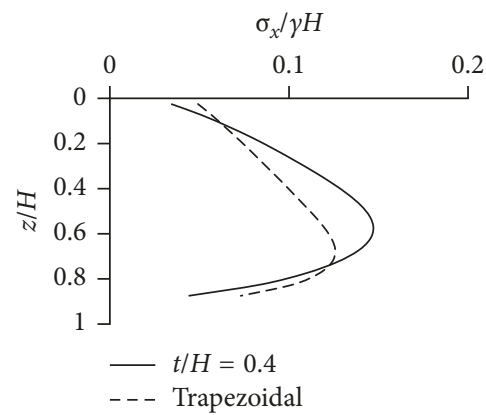

(f)

FIGURE 10: Effect of trapezoidal geofoam panel and one rectangular geofoam panel with the relative thickness of $0.4 \mathrm{H}$ on $(\mathrm{a}, \mathrm{b}$, and c) lateral displacements of soil and ( $\mathrm{d}, \mathrm{e}$, and $\mathrm{f}$ ) distribution of forces on nonyielding retaining walls. (a) $H=3 \mathrm{~m}$. (b) $H=6 \mathrm{~m}$. (c) $H=9 \mathrm{~m}$. (d) $H=3 \mathrm{~m}$. (e) $H=6 \mathrm{~m}$. (f) $H=9 \mathrm{~m}$.

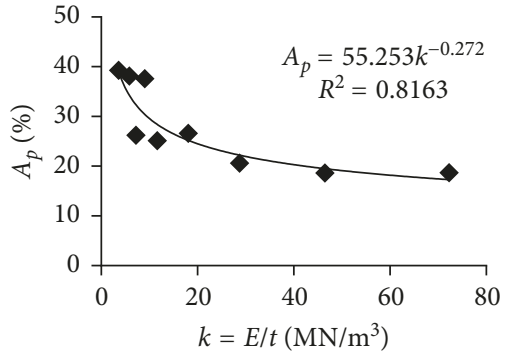

(a)

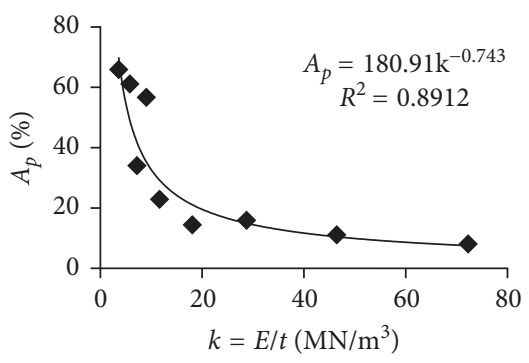

(d)

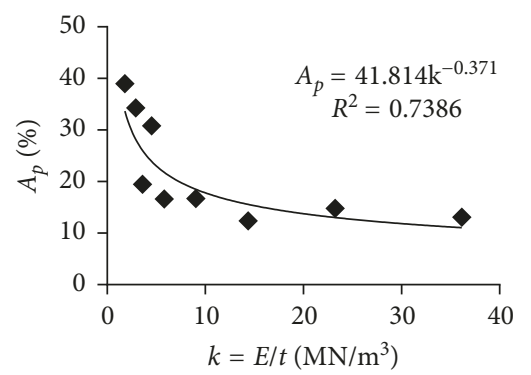

(b)

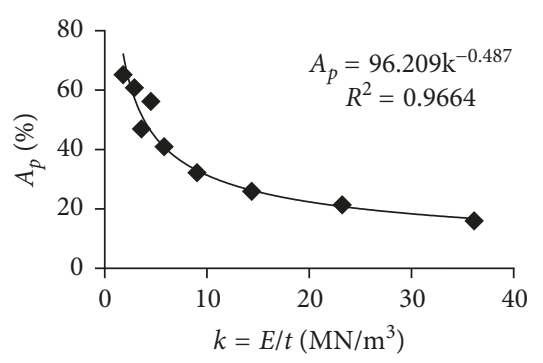

(e)

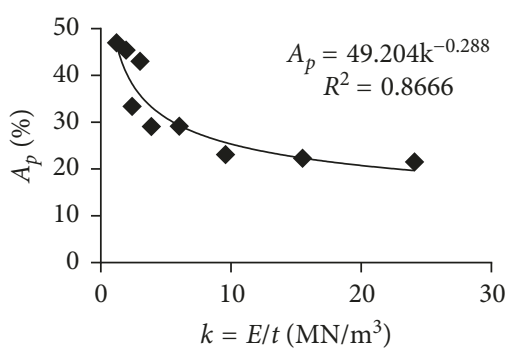

(c)

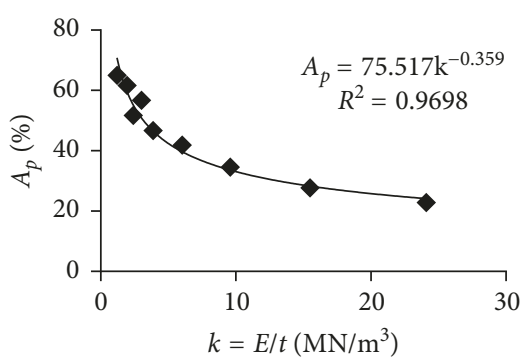

(f)

Figure 11: Influence of stiffness of geofoam $(k=E / t)$ on the reduction of forces on retaining walls: $(\mathrm{a}, \mathrm{b}$, and $\mathrm{c})$ yielding retaining wall and (d, e, and f) nonyielding retaining wall. (a) $H=3 \mathrm{~m}$. (b) $H=6 \mathrm{~m}$. (c) $H=9 \mathrm{~m}$. (d) $H=3 \mathrm{~m}$. (e) $H=6 \mathrm{~m}$. (f) $H=9 \mathrm{~m}$. 

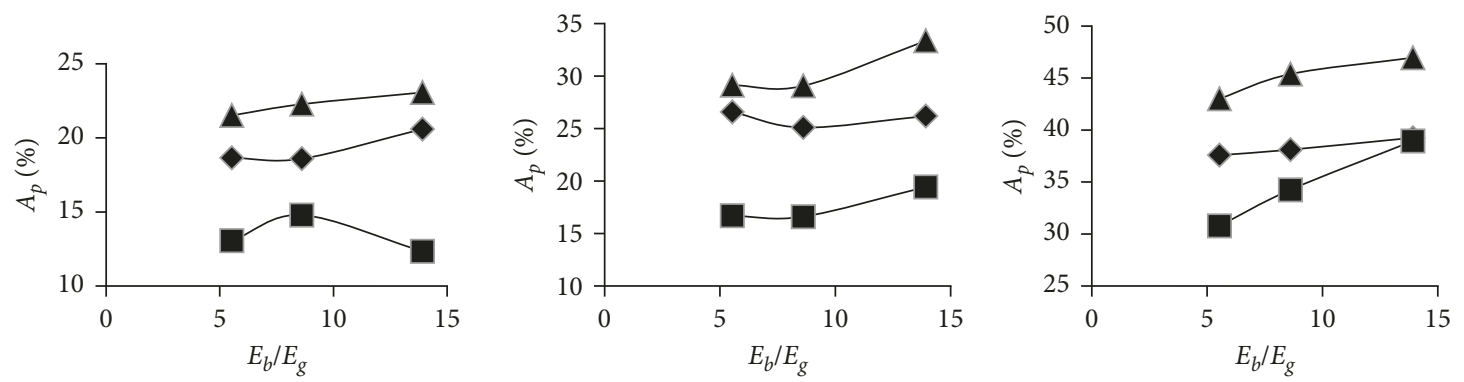

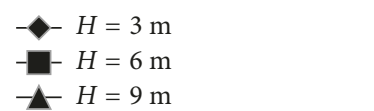

(a)

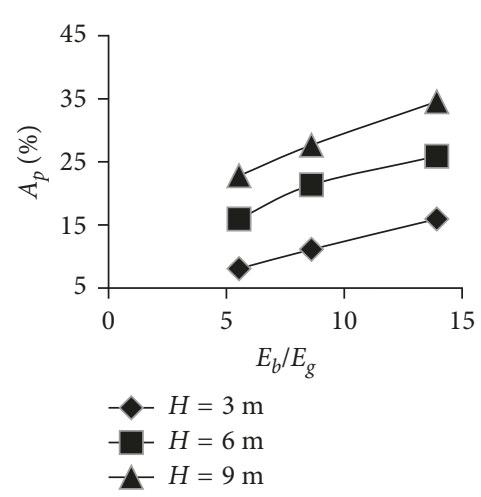

(d)

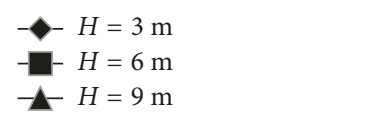

(b)

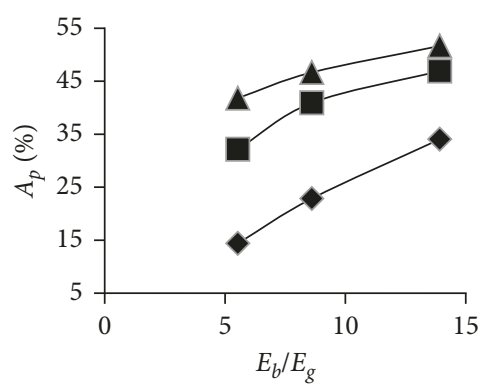

- $H=3 \mathrm{~m}$

$H=6 \mathrm{~m}$

$H=9 \mathrm{~m}$

(e)

$$
\begin{aligned}
& \text { - }-H=3 \mathrm{~m} \\
& H=6 \mathrm{~m}
\end{aligned}
$$

(c)

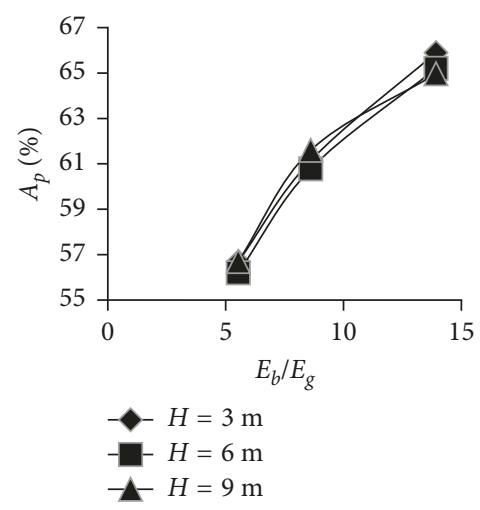

(f)

FIGURE 12: Influence of relative stiffness of geofoam $\left(E_{b} / E_{g}\right)$ on the reduction of forces on retaining walls: (a, b, and c) yielding retaining walls and (d, e, and f) nonyielding retaining walls. (a) $t / H=0.05$. (b) $t / H=0.2$. (c) $t / H=0.4$. (d) $t / H=0.05$. (e) $t / H=0.2$. (f) $t / H=0.4$.

TABLE 5: Cantilever retaining wall factors of safety.

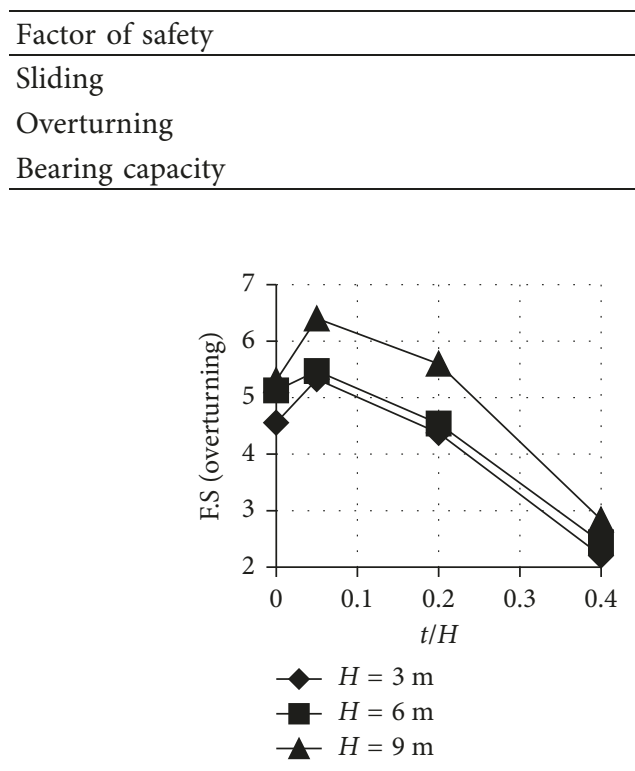

(a)

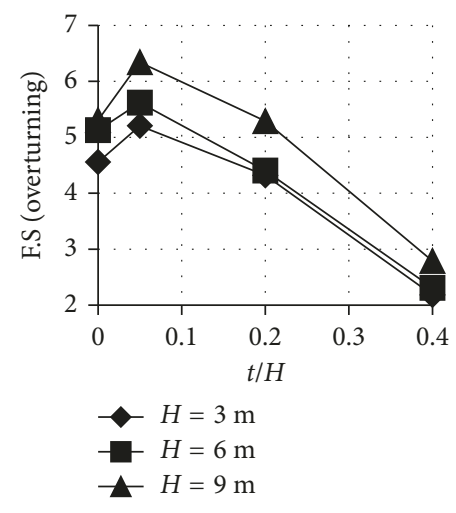

(b)

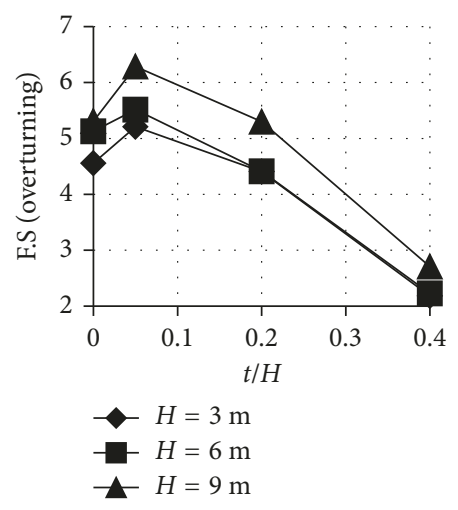

(c)

FIGURE 13: Influence of the geofoam thickness ratio on the overturning safety factor of yielding retaining walls. (a) EPS15. (b) EPS20. (c) EPS25. 
TABLE 6: Normal interface stiffness for the $3 \mathrm{~m}$ and $6 \mathrm{~m}$ high walls.

\begin{tabular}{lr}
\hline Interface & Normal stiffness, $k_{n}\left(\frac{\mathrm{MPa}}{m}\right)$ \\
\hline Between wall and foundation soil & $4.94 \times 10^{3}$ \\
Between wall and backfill soil & $2.96 \times 10^{3}$ \\
Between wall and EPS & $1.46 \times 10^{2}$ to $7.57 \times 10^{2}$ \\
Between EPS and foundation soil & $1.46 \times 10^{2}$ \\
Between EPS and backfill soil & $1.46 \times 10^{2}$ to $7.57 \times 10^{2}$ \\
\hline
\end{tabular}

TABle 7: Normal interface stiffness for the $9 \mathrm{~m}$ high wall.

\begin{tabular}{lr}
\hline Interface & Normal stiffness, $k_{n}\left(\frac{\mathrm{MPa}}{m}\right)$ \\
\hline Between wall and foundation soil & $3.29 \times 10^{3}$ \\
Between wall and backfill soil & $1.98 \times 10^{3}$ \\
Between wall and EPS & $9.7 \times 10^{1}$ to $2.52 \times 10^{2}$ \\
Between EPS and foundation soil & $9.7 \times 10^{1}$ \\
Between EPS and backfill soil & $9.7 \times 10^{1}$ to $2.52 \times 10^{2}$ \\
\hline
\end{tabular}

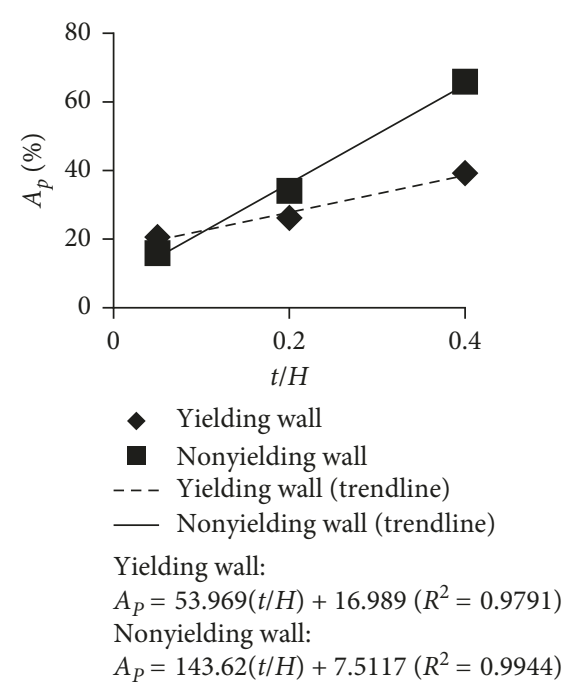

(a)

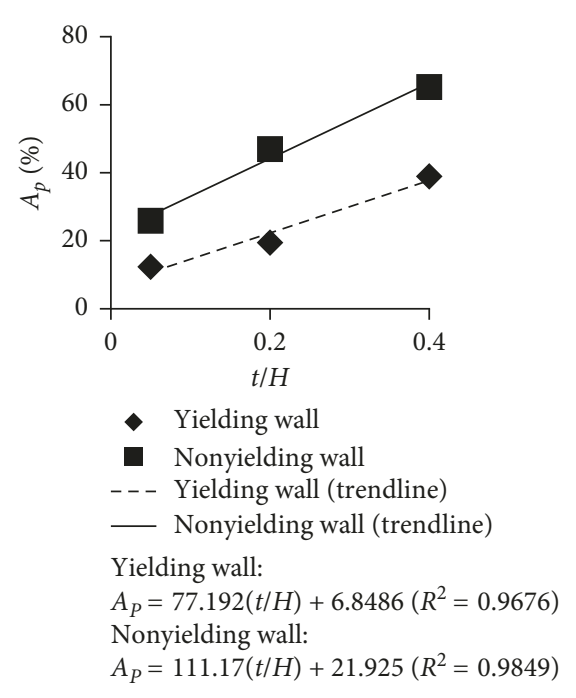

(b)

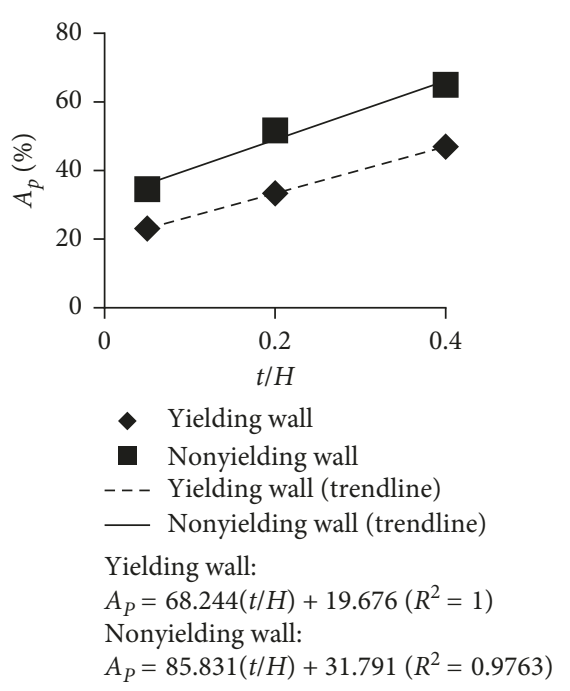

(c)

FIGURE 14: Influence of the EPS15 thickness ratio on reduction of lateral pressure.

(4) Trapezoidal geofoam increases soil lateral displacement and reduces forces on retaining walls compared to a rectangular geofoam panel (with equal cross section).

(5) According to the present study, increasing the geofoam thickness reduces forces on cantilever retaining walls. Therefore, geofoam with the relative thickness up to $0.05 \mathrm{H}$ improves the overturning safety factor of retaining walls. However, it is not recommended to use geofoam with the relative thickness higher than $0.2 \mathrm{H}$ in the yielding cantilever retaining walls due to a reduction of resistive forces and stability reduction of such walls against overturning. At a thickness of $0.4 \mathrm{H}$, the overturning safety factor of yielding retaining walls is reduced by $50 \%$.
(6) Effect of geofoam on the reduction of forces on nonyielding cantilever retaining walls is more than that on yielding walls. Therefore, geofoam is mostly used to reduce static forces on nonyielding retaining walls.

\section{Appendices}

\section{A. Normal Interface Stiffness Values}

Details related to the stiffness of the materials' interface for retaining walls have been shown in Tables 6 and 7 $\left(k_{s}=0.2 k_{n}\right)$. 


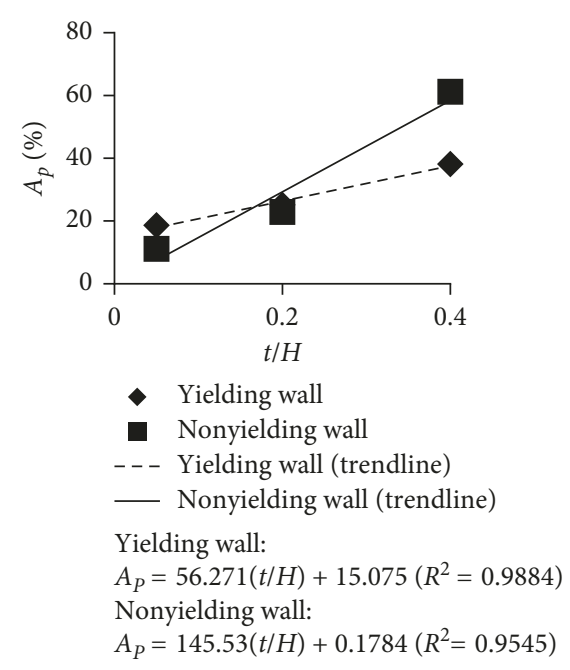

(a)

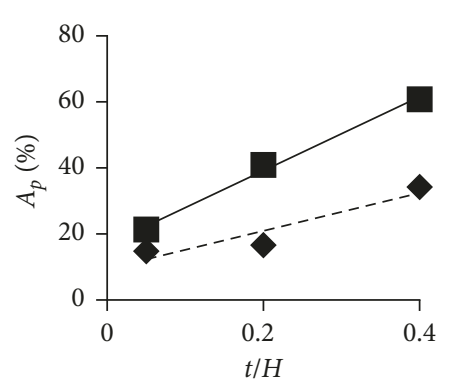

- Yielding wall

- Nonyielding wall

- . - Yielding wall (trendline)

__ Nonyielding wall (trendline)

Yielding wall:

$A_{P}=57.39(t / H)+9.4462\left(R^{2}=0.8783\right)$

Nonyielding wall:

$A_{P}=111.93(t / H)+16.765\left(R^{2}=0.9939\right)$

(b)

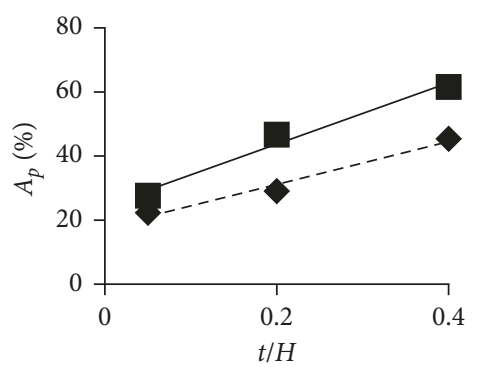

- Yielding wall

- Nonyielding wall

- Yielding wall (trendline)

_ Nonyielding wall (trendline)

Yielding wall:

$A_{P}=66.871(t / H)+17.752\left(R^{2}=0.9772\right)$

Nonyielding wall:

$A_{P}=95.779(t / H)+24.552\left(R^{2}=0.9771\right)$

(c)

FIGURE 15: Influence of the EPS20 thickness ratio on reduction of lateral pressure.

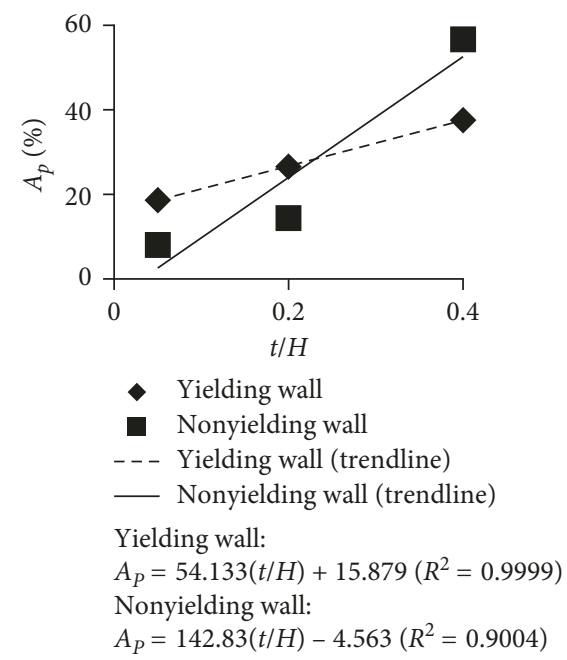

(a)

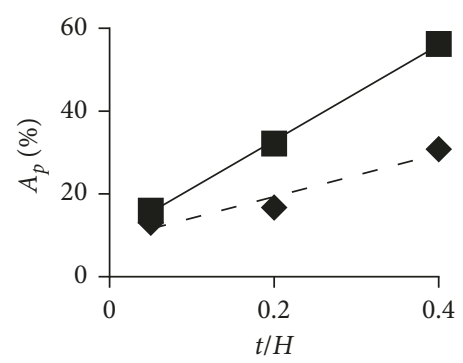

$$
\begin{array}{ll}
\quad \text { Yielding wall } \\
\text { - } & \text { Nonyielding wall } \\
-- & \text { Yielding wall (trendline) } \\
\hline & \text { Nonyielding wall (trendline) }
\end{array}
$$

Yielding wall:

$A_{P}=51.739(t / H)+8.9687\left(R^{2}=0.9407\right)$

Nonyielding wall:

$A_{P}=115.26(t / H)+9.8053\left(R^{2}=0.9991\right)$

(b)

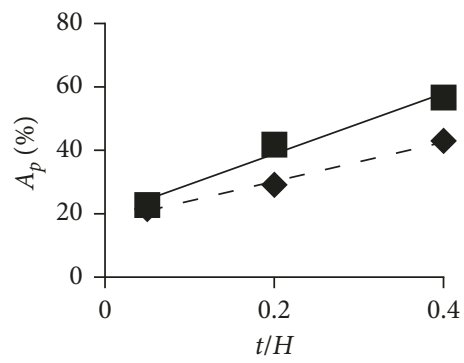

- Yielding wall

- Nonyielding wall

- - Yielding wall (trendline)

_ Nonyielding wall (trendline)

Yielding wall:

$A_{P}=61.835(t / H)+17.823\left(R^{2}=0.9929\right)$

Nonyielding wall:

$A_{P}=95.669(t / H)+19.706\left(R^{2}=0.9768\right)$

(c)

FIGURE 16: Influence of the EPS25 thickness ratio on reduction of lateral pressure.

\section{B. Effect of Geofoam Thickness Ratio on Reduction of Lateral Pressure}

Figures 14-16. show a reduction of forces on yielding and nonyielding retaining walls in the cases of using EPS15, EPS20, and EPS25, respectively.

\section{Nomenclature}

$A_{P}: \quad$ Reduction in statical forces on retaining walls (\%)

$B$ : $\quad$ Cantilever retaining wall base width $(\mathrm{m})$

$b_{h}$ : Cantilever retaining wall heel breadth $(\mathrm{m})$

$b_{t}$ : Cantilever retaining wall toe extension $(\mathrm{m})$

$C$ : $\quad$ Cohesion of geofoam $(\mathrm{kPa})$

$d$ : Geofoam panel spacing $(\mathrm{cm})$

$E_{\mathrm{ti}}$ : Young's modulus of geofoam $(\mathrm{MPa})$
G: $\quad$ Shear modulus $(\mathrm{MPa})$

$H$ : $\quad$ Cantilever retaining wall height $(\mathrm{m})$

$k$ : $\quad$ Stiffness of geofoam $\left(\mathrm{MN} / \mathrm{m}^{3}\right)$

$K: \quad$ Bulk modulus (MPa)

$k_{n}$ : $\quad$ Normal interface stiffness $(\mathrm{MPa} / \mathrm{m})$

$k_{s}: \quad$ Shear interface stiffness $(\mathrm{MPa} / \mathrm{m})$

$t$ : Geofoam thickness (m)

$t_{b}$ : Cantilever retaining wall base thickness $(\mathrm{m})$

$t_{s}$ : $\quad$ Cantilever retaining wall stem thickness $(\mathrm{m})$

$\gamma_{g}: \quad$ Specific weight of geofoam $\left(\mathrm{kN} / \mathrm{m}^{3}\right)$

$\delta_{x}: \quad$ Lateral displacements of soil $(\mathrm{m})$

$\Delta z_{\text {min }}$ : Smallest width of an adjoining zone in the normal direction (m)

$v$ : Poisson's ratio of geofoam (dimensionless)

$\rho$ : Density of geofoam $\left(\mathrm{kg} / \mathrm{m}^{3}\right)$ 
$\sigma_{x}: \quad$ Lateral stress on cantilever retaining wall $(\mathrm{kPa})$

$\sigma_{y}: \quad$ Yield strength of geofoam $(\mathrm{kPa})$.

\section{Conflicts of Interest}

The authors declare that there are no conflicts of interest.

\section{References}

[1] A. M. Partos and P. M. Kazaniwsky, "Geoboard reduces lateral earth pressures," in Proceedings of Geosynthetics 87, Industrial Fabrics Association International, pp. 628-639, New Orleans, LA, USA, February 1987.

[2] R. Karpurapu and R. J. Bathurst, "Numerical investigation of controlled yielding of soil-retaining wall structures," Geotextiles and Geomembranes, vol. 11, no. 2, pp. 115-131, 1992.

[3] M. Koerner Robert, Designing with Geosynthetics, Pearson Education, London, UK, 5th edition, 2005.

[4] B. R. R. Lal, A. H. Padade, and J. N. Mandal, "Numerical simulation of EPS geofoam as compressible inclusions in fly ash backfill retaining walls," in Proceedings of Ground Improvement and Geosynthetics, pp. 526-535, Shanghai, China, June 2014.

[5] S. A. Azzam and S. S. AbdelSalam, "EPS geofoam to reduce lateral earth pressure on rigid walls," in Proceedings of International Conference on Advances in Structural and Geotechnical Engineering, Hurghada, Egypt, March 2015.

[6] S. S. AbdelSalam and S. A. Azzam, "Reduction of lateral pressures on retaining walls using geofoam inclusion," Geosynthetics International, vol. 23, no. 6, pp. 395-407, 2016.

[7] P. Ni, G. Mei, and Y. Zhao, "Displacement-dependent earth pressures on rigid retaining walls with compressible geofoam inclusions: physical modeling and analytical solutions," International Journal of Geomechanics, vol. 17, no. 6, p. 04016132, 2016.

[8] A. C. Trandafir and S. F. Bartlett, "Seismic performance of double EPS geofoam buffer systems," in Proceedings of Fifth International Conference on Recent Advances in Geotechnical Earthquake Engineering and Soil Dynamics and Symposium in Honor of Professor I. M. Idriss, p. 5.10a, San Diego, CA, USA, May 2010.

[9] S. Zarnani and R. J. Bathurst, "Numerical parametric study of geofoam seismic buffers with different constitutive models," in Proceedings of 9th International Conference on Geosynthetics, pp. 1665-1670, Guaruja, Brazil, September 2010.

[10] A. Athanasopoulos Zekkos, K. Lamote, and G. A. Athanasopoulos, "Use of EPS geofoam compressible inclusions for reducing the earthquake effects on yielding earth retaining structures," Soil Dynamics and Earthquake Engineering, vol. 41, pp. 59-71, 2012.

[11] T. Stark, S. Bartlett, and D. Arellano, Expanded Polystyrene (EPS) Geofoam Applications \& Technical Data, EPS Industry Alliance, Crofton, MD, USA, 2011, http://www.beaverplastics. com/Geotechnical/documents/geofoam_app_and_tech_data. pdf.

[12] A. H. Padade and J. N. Mandal, "Behavior of expanded polystyrene (EPS) geofoam under triaxial loading conditions," Electronic Journal of Geotechnical Engineering, vol. 17, pp. 2543-2553, 2012.

[13] O. Ertugrul and A. Trandafir, "Reduction of lateral earth forces acting on rigid nonyielding retaining walls by EPS geofoam inclusions," Journal of Materials in Civil Engineering, vol. 23, no. 12, pp. 1711-1718, 2011.
[14] A. Trandafir, J. Moyles, and B. Erickson, "Finite-element analysis of lateral pressures on rigid non-yielding retaining walls with EPS geofoam inclusion," in Proceedings of Earth Retention Conference, pp. 756-763, Bellevue, WA, USA, August 2010.

[15] O. Ertugrul and A. Trandafir, "Lateral earth pressures on flexible cantilever retaining walls with deformable geofoam inclusions," Engineering Geology, vol. 158, pp. 23-33, 2013.

[16] S. S. AbdelSalam, S. A. Azzam, and B. M. Fakhry, "Reliability and 3D modeling of flexible walls with EPS inclusion," International Journal of Geomechanics, vol. 17, no. 7, 2017.

[17] S. Zarnani and R. J. Bathurst, "Numerical parametric study of expanded polystyrene (EPS) geofoam seismic buffers," Canadian Geotechnical Journal, vol. 46, no. 3, pp. 318-338, 2009.

[18] C. H. Clayton, R. Woods, A. Bond, and J. Milititsky, Earth pressure and Earth-retaining Structures, CRC Press, Boca Raton, FL, USA, 3rd edition, 2013.

[19] T. Stark, D. Arellano, J. S. Horvath, and D. Leshchinsky, Geofoam Applications in the Design and Construction of Highway Embankments, NCHRP Web Document 65 (Project 24-11), Transportation Research Board, Washington, DC, USA, 2004.

[20] G. A. Athanasopoulos, P. C. Pelekis, and V. C. Xenaki, "Dynamic properties of EPS geofoam: an experimental investigation," Geosynthetics International, vol. 6, no. 3, pp. 171-194, 1999.

[21] J. S. Horvath, "The compressible inclusion function of EPS geofoam," Geotextiles and Geomembranes, vol. 15, no. 1-3, pp. 77-120, 1997.

[22] Itasca, "FLAC manual (fast lagrangian analysis of continua), version 7.0," Itasca Consulting Group, Inc., Minneapolis, MN, USA, 2011.

[23] A. Bhattacharjee and A. Murali Krishna, Study of Seismically Induced Permanent Displacement of Gravity Retaining Wall, pp. 627-631, Indian Geotechnical Society, Guntur, India, 2009.

[24] A. Chugh and J. Labuz, "Numerical simulation of an instrumented cantilever retaining wall," Canadian Geotechnical Journal, vol. 48, no. 9, pp. 1303-1313, 2011.

[25] Q. Xie, C. D. Gama, X. Yu, and Y. Chen, "A parametric study of interface characteristics in a buttress retaining wall," Electronic Journal of Geotechnical Engineering, vol. 18, pp. 1477-1492, 2013.

[26] G. A. Athanasopoulos, C. Nikolopoulou, and V. Xenaki, "Seismic isolation of earth retaining structures by EPS geofoam compressible inclusions-dynamic FE analyses," in Proceedings of 4th International Conference on Earthquake Geotechnical Engineering, p. 1676, San Diego, CA, USA, March 2007. 


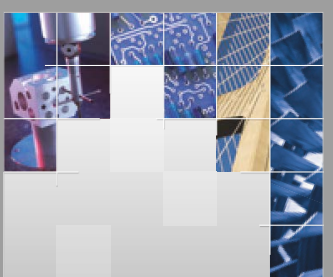

\section{Enfincering}
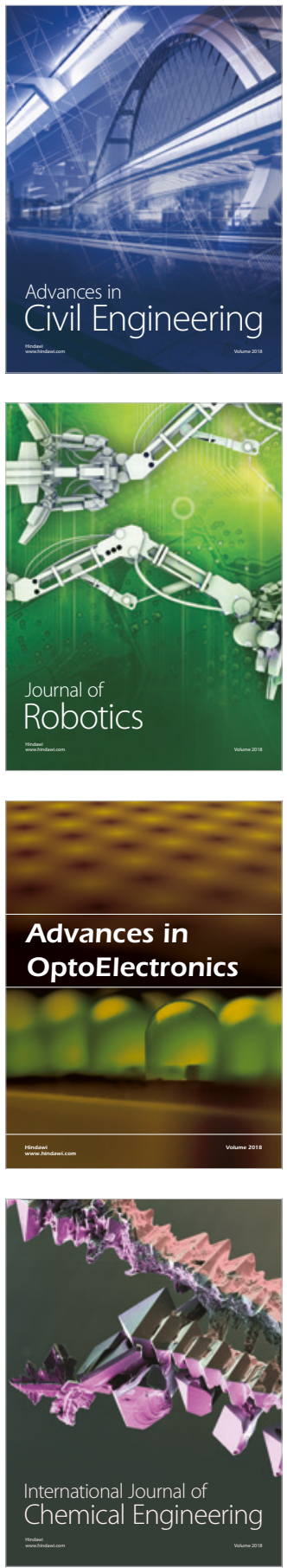

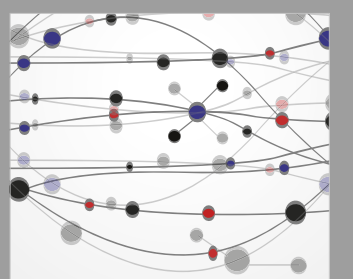

\section{Rotating \\ Machinery}

The Scientific World Journal

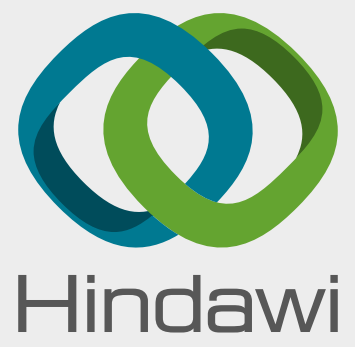

Submit your manuscripts at

www.hindawi.com
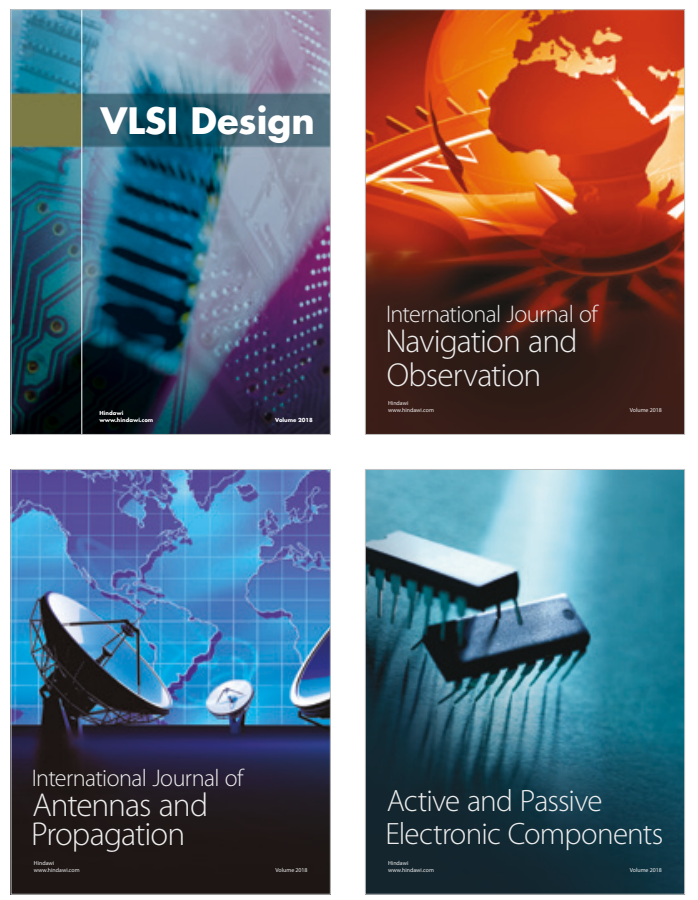
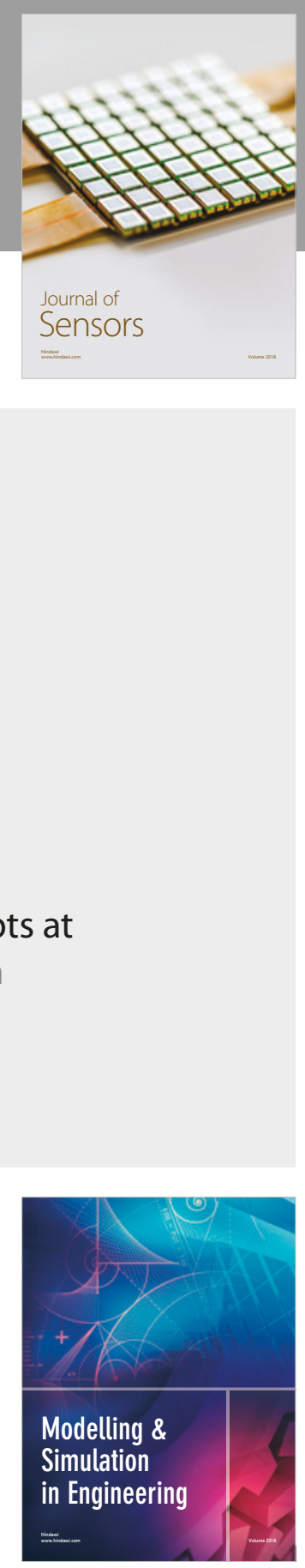

\section{Advances \\ Multimedia}
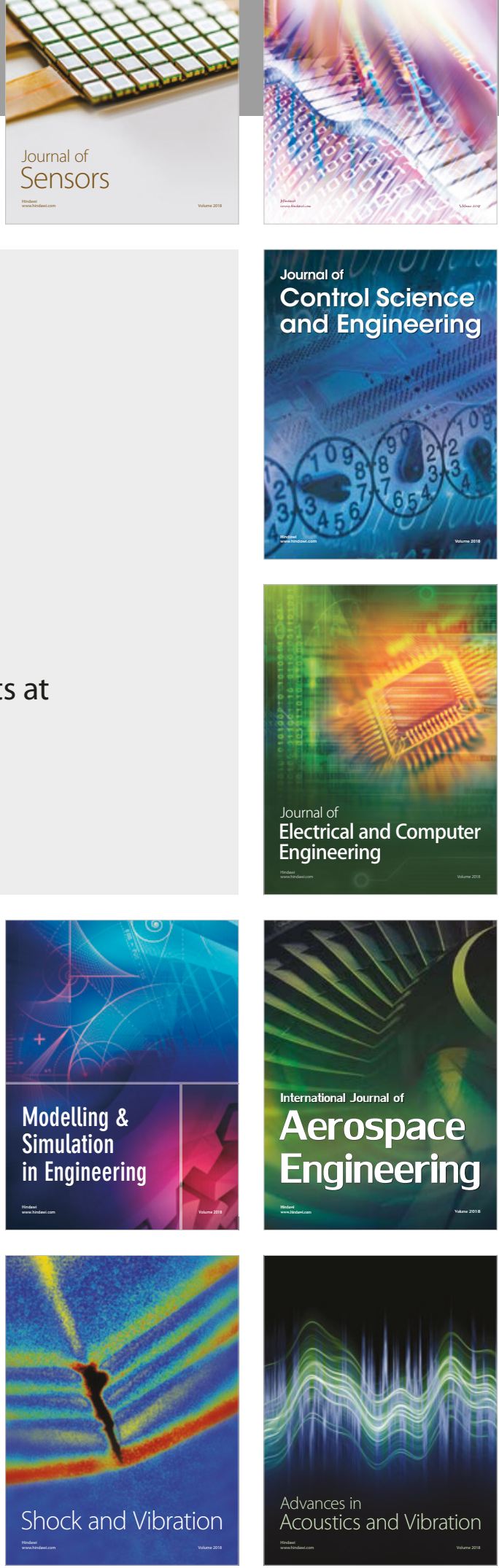